\title{
Above-cloud aerosol radiative effects based on ORACLES 2016 and ORACLES 2017 aircraft experiments
}

\author{
Sabrina P. Cochrane ${ }^{1,2}$, K. Sebastian Schmidt ${ }^{1,2}$, Hong Chen ${ }^{1,2}$, Peter Pilewskie ${ }^{1,2}$, Scott Kittelman ${ }^{1}$, Jens Redemann ${ }^{3}$, \\ Samuel LeBlanc ${ }^{4,5}$, Kristina Pistone ${ }^{4,5}$, Meloë Kacenelenbogen ${ }^{5}$, Michal Segal Rozenhaimer ${ }^{4,5,6}$, Yohei Shinozuka ${ }^{5,7}$, \\ Connor Flynn $^{8}$, Steven Platnick ${ }^{9}$, Kerry Meyer ${ }^{9}$, Rich Ferrare ${ }^{10}$, Sharon Burton ${ }^{10}$, Chris Hostetler ${ }^{10}$, \\ Steven Howell ${ }^{11}$, Steffen Freitag ${ }^{11}$, Amie Dobracki ${ }^{12}$, and Sarah Doherty ${ }^{13}$ \\ ${ }^{1}$ Department of Atmospheric and Oceanic Sciences, University of Colorado, Boulder, CO 80303, USA \\ ${ }^{2}$ Laboratory for Atmospheric and Space Physics, University of Colorado, Boulder, CO 80303, USA \\ ${ }^{3}$ School of Meteorology, University of Oklahoma, Norman, OK 73019, USA \\ ${ }^{4}$ Bay Area Environmental Research Institute, Mountain View, CA 94035, USA \\ ${ }^{5}$ NASA Ames Research Center, Mountain View, CA 94035, USA \\ ${ }^{6}$ Department of Geophysics and Planetary Sciences, Porter School of the Environment and Earth Sciences, \\ Tel-Aviv University, Tel-Aviv, Israel \\ ${ }^{7}$ Universities Space Research Association, Mountain View, CA 94035, USA \\ ${ }^{8}$ Pacific Northwest National Laboratory, Richland, WA 99354, USA \\ ${ }^{9}$ NASA Goddard Space Flight Center, Greenbelt, MD 20771, USA \\ ${ }^{10}$ NASA Langley Research Center, Hampton, VA 23666, USA \\ ${ }^{11}$ Department of Oceanography, University of Hawaii, Honolulu, HI 96844, USA \\ ${ }^{12}$ Department of Atmospheric Science, Rosentiel School of Marine and Atmospheric Science, \\ University of Miami, Miami, FL 33146, USA \\ ${ }^{13}$ Joint Institute for the Study of Atmosphere and Ocean, University of Washington, Seattle, WA 98195, USA
}

Correspondence: Sabrina P. Cochrane (sabrina.cochrane@ colorado.edu)

Received: 28 March 2019 - Discussion started: 26 April 2019

Revised: 16 August 2019 - Accepted: 16 October 2019 - Published: 9 December 2019

\begin{abstract}
Determining the direct aerosol radiative effect (DARE) of absorbing aerosols above clouds from satellite observations alone is a challenging task, in part because the radiative signal of the aerosol layer is not easily untangled from that of the clouds below. In this study, we use aircraft measurements from the NASA ObseRvations of CLouds above Aerosols and their intEractionS (ORACLES) project in the southeastern Atlantic to derive it with as few assumptions as possible. This is accomplished by using spectral irradiance measurements (Solar Spectral Flux Radiometer, SSFR) and aerosol optical depth (AOD) retrievals (Spectrometer for Sky-Scanning, Sun-Tracking Atmospheric Research, 4STAR) during vertical profiles (spirals) that minimize the albedo variability of the underlying cloud field thus isolating aerosol radiative effects from those of the cloud field below. For two representative cases, we retrieve spectral
\end{abstract}

aerosol single scattering albedo (SSA) and the asymmetry parameter $(g)$ from these profile measurements and calculate DARE given the albedo range measured by SSFR on horizontal legs above clouds. For mid-visible wavelengths, we find SSA values from 0.80 to 0.85 and a significant spectral dependence of $g$. As the cloud albedo increases, the aerosol increasingly warms the column. The transition from a cooling to a warming top-of-aerosol radiative effect occurs at an albedo value (critical albedo) just above 0.2 in the midvisible wavelength range. In a companion paper, we use the techniques introduced here to generalize our findings to all 2016 and 2017 measurements and parameterize aerosol radiative effects. 


\section{Introduction}

\subsection{Background}

Aerosols are ubiquitous throughout the Earth's atmosphere, and they play a crucial role in modulating the flux of solar radiation that reaches the Earth's surface. The energy distribution within a scene that contains aerosols depends not only on the amount of incoming solar radiation, aerosol optical depth (AOD), and type, but also on the albedo beneath the aerosols. Depending on the type of aerosol, the incoming radiation will be absorbed or scattered in a certain ratio, described by the single scattering albedo (SSA), while the direction (forward or backward) of the scattered radiation can be approximated by the asymmetry parameter $(g)$. Aerosol absorption and scattering change the radiative balance relative to the aerosol-free atmosphere. This perturbation is called the direct aerosol radiative effect (DARE). The scene albedo below an aerosol layer, whether from clouds, ocean, or land, can determine whether the layer has a negative (positive) DARE, resulting in a cooling (warming) effect at the top of the atmosphere (Twomey, 1977; Russell et al., 2002). Aerosols injected into the global climate system by human activity since the beginning of industrialization may offset up to $50 \%$ of the warming due to anthropogenic greenhouse gas emissions (Myhre et al., 2013). However, the uncertainty of this offset is large, in part due to observational challenges: radiative forcing by anthropogenic aerosol-radiation interactions could range from -1 to $+0.2 \mathrm{~W} \mathrm{~m}^{-2}$ (Fig. 8.15 in Myhre et al., 2013).

Deriving the direct effect of aerosols on the radiation budget, ignoring for the moment the impact on radiative balance due to aerosol influences on cloud properties and lifetime, is difficult since DARE is derived from the difference between radiative fluxes in the presence of and absence of aerosol. It is impossible to observe both states simultaneously, and therefore, DARE is not directly measurable and, in most cases, requires a radiative transfer model (RTM) initialized with observational or model inputs of aerosol AOD, SSA, and $g$ as well as the spectral reflectance or albedo below the aerosol layer. The DARE calculations are limited by the accuracy of the observations and the model accuracy itself. For conditions where absorbing aerosols overlie inhomogeneous cloud fields, determining DARE is even more challenging since the calculations require both the aerosol properties as well as the cloud properties, primarily the cloud spectral albedo. The cloud radiative signal can be relatively large compared to that of aerosol particles. Therefore, it can be difficult to isolate the aerosol radiative effect from that of clouds, especially when the cloud albedo varies in the sampling region.

\subsection{Satellite-derived cloud and aerosol properties to derive DARE}

Obtaining the necessary cloud and aerosol parameters from satellite instruments provides the flexibility to estimate DARE in nearly any region. Until recently, aerosol and cloud properties could not typically be measured from the same satellite when the aerosol occurs above the clouds, and the strategy to estimate DARE for these conditions was to combine properties from multiple satellites (e.g., Chand et al., 2009; Meyer et al., 2013; Zhang et al., 2016; Sayer at al. 2016; Kacenelenbogen et al., 2019; Oikawa et al., 2018; Korras-Carraca et al., 2019). The problem with this approach, however, is that biases in the cloud and aerosol properties translate into biases in DARE if left unaccounted for (Meyer et al., 2013). For example, many DARE studies utilize Moderate Resolution Imaging Spectroradiometer (MODIS) cloud optical thickness (COT) and effective droplet size (translated into cloud albedo, which cannot be directly measured from space) and/or AOD from the active lidar instrument Cloud-Aerosol Lidar with Orthogonal Polarization (CALIOP). However, MODIS cloud retrievals can be biased when absorbing aerosols are present above cloud (Haywood et al., 2004; Wilcox et al., 2009; Coddington et al., 2010) and CALIOP AOD, which was known to be lowbiased for daytime measurements (Kacenelenbogen et al., 2011; Winker et al., 2013; Meyer et al., 2013; Jethva et al., 2014) until the development of a new method in version 4 to derive AOD above cloud that uses the cloud returns to derive a much more accurate measure of AOD above cloud (Kim et al., 2018).

Work has been done to characterize and correct for the biases in cloud and aerosol properties in DARE estimates (Meyer et al., 2013; Zhang et al., 2016). Meyer et al. (2015) account for the satellite cloud optical property bias by developing a simultaneous retrieval of cloud optical thickness and effective radius and aerosol AOD from MODIS imagery alone, thus obtaining both aerosol and cloud properties from a single instrument that are used as inputs into DARE calculations. Jethva et al. (2013) also retrieve AOD and COT from MODIS alone, using the color ratio method to derive DARE.

Table 1 in Kacenelenbogen et al. (2019) provides a summary of DARE studies and the methods used to obtain aerosol and cloud properties, and it is clear that although methods to account for satellite AOD and COT biases have been established, the aerosol SSA and $g$ remain difficult to obtain. Often, SSA and $g$ are obtained from an assumed aerosol model, such as the MODIS MOD04 absorbing aerosol model used in Meyer et al. $(2013,2015)$ or the CALIOP aerosol sub-type models used by Zhang et al. (2016). This approach requires the correct aerosol model to be chosen, and some studies choose instead to use optical properties from an outside source. For example, Chand et al. (2009) combine CALIPSO aerosol AOD and Ångström exponent with MODIS COT, but assume a regional mean 
Table 1. Case description: spiral.

\begin{tabular}{lll}
\hline Date & 20 September 2016 & 13 August 2017 \\
\hline UTC & {$[11: 55,12: 14]$} & {$[10: 05,10: 15]$} \\
Latitude range & {$[-16.79,-16.61]$} & {$[-9.02,-8.90]$} \\
Longitude range & {$[8.80,8.99]$} & {$[4.88,5.00]$} \\
Cloud top albedo & 0.45 & 0.70 \\
[501 nm $]$ & & \\
Solar zenith angle & 21.0 & 33.5 \\
\hline
\end{tabular}

value of SSA from the Southern African Regional Science Initiative (SAFARI) 2000 campaign to derive diurnal DARE. Jethva et al. (2013) estimate DARE using the SSA obtained from Aerosol Robotic Network (AERONET) sites. Since these measurements of SSA are not taken in conjunction with the other cloud and aerosol properties, it is difficult to determine whether they are valid and consistent for the specific aerosol measured by the satellite.

Some studies, such as Peers et al. (2015) and de Graaf et al. (2012), have developed unique methods for which aerosol properties are not assumed. Peers et al. (2015) derive aerosol and cloud properties simultaneously through polarization measurements made by the Polarization and Directionality of Earth Reflectances (POLDER) instrument on the PARASOL satellite, while de Graaf et al. (2012) avoid the aerosol properties altogether and simulate a cloud-only sky and compare this to measured hyperspectral reflectances from the Scanning Imaging Absorption Spectrometer for Atmospheric Chartography (SCIAMACHY). de Graaf et al. (2019) compare DARE from these two methods along with DARE derived from OMI and MODIS for the southeastern Atlantic region, finding that DARE is correlated between all methods for moderate values of DARE. However, POLDER-derived values are higher than the other two methods for higher DARE values, which they attribute to larger cloud optical thickness retrievals by POLDER.

\subsection{Estimates of DARE from aircraft observations}

Aircraft observations, as opposed to satellite remote sensing, provide in situ observations of clouds and aerosols that are better suited for deriving their radiative properties, especially when the clouds are inhomogeneous. For example, an aircraft can fly through an aerosol layer to measure aerosol absorption, scattering, and SSA with in situ instruments or fly directly above a cloud layer to measure the albedo. Studies such as Pilewskie et al. (2003), Redemann et al. (2006), Schmidt et al. (2010a), Coddington et al. (2010), LeBlanc et al. (2012), and Ehrlich et al. (2017) along with the work presented here have capitalized on this versatility and developed new algorithms and instrumentation to determine aerosol and cloud properties, which can then be utilized to estimate DARE.
For example, under the specific conditions of an aerosol layer with a loading gradient above a homogenous, dark surface, Redemann et al. (2006) derived the below-layer aerosol forcing efficiency (radiative effect per mid-visible AOD) from the co-varying irradiance/AOD pairs along a leg with minimal dependence on radiative transfer calculations. This method, however, is not applicable for scenes with absorbing aerosols above clouds such as those encountered during the recent NASA ObseRvations of CLouds above Aerosols and their intEractionS (ORACLES) project (Zuidema et al., 2016). The ORACLES project conducted three aircraft campaigns in the southeastern Atlantic, providing measurements in a region with high biomass burning aerosol loading where there have been few extensive field observations to date. In this study, we combine data from multiple instruments to retrieve the aerosol and cloud properties as directly as possible in order to calculate DARE and investigate the relationship between DARE and cloud albedo. The sensitivity of DARE above the aerosol layer to the underlying surface can be described by the transition from a negative to a positive radiative effect, or cooling to warming (Russell et al., 2002). The albedo where this transition occurs, hereafter called the critical albedo, expands upon the quantities of critical reflectance and critical surface albedo that more specifically refer to the relationship between AOD and top of atmosphere reflectance (Fraser and Kaufman, 1985; Seidel and Popp, 2012). The dependence of the sign of the aerosol's radiative effect on the underlying albedo has been shown for aerosols above clouds in the southeastern Atlantic by Keil and Haywood (2003), Chand et al. (2009), and Meyer et al. (2013).

ORACLES aircraft observations make up an extensive dataset that can be used to validate current satellite methods of deriving the aerosol and cloud properties that go into calculations of DARE. To begin this process, our primary objective of this paper is to derive DARE as a function of (a) the aerosol optical properties and (b) cloud albedo from the ORACLES measurements. In Sect. 2, we describe the observations themselves and the sampling approaches used to obtain them. Section 3 describes the methods used to determine SSA and $g$ and how we utilize the results to calculate DARE as directly as possible. Section 4 presents our findings, while Sect. 5 provides a discussion and ways in which we will explore DARE's dependence on aerosol properties in the future, along with prospective satellite validation goals.

\section{Observations: measurement techniques, instrumentation, and data}

\subsection{ORACLES}

The first two deployments of the NASA ORACLES experiment were conducted from Namibia in 2016 and from São Tomé in 2017, regions located on or just off the western coast of the African continent. The southeastern Atlantic Ocean is 
often covered by a seasonal stratocumulus cloud deck capped by a thick layer of biomass burning aerosols advected from the interior of the African continent, providing ideal natural conditions to assess aerosol radiative effects above various cloud scenes and improve the understanding of many aspects of cloud-aerosol interactions.

Both the NASA P-3 and the ER-2 aircraft were deployed in the 2016 campaign. The P-3 flew at approximately $5 \mathrm{~km}$ altitude and below, carrying a comprehensive payload of both in situ and remote sensing instruments. The ER-2 flew at high altitude, approximately $20 \mathrm{~km}$, carrying remote sensing instruments such as the enhanced MODIS Airborne Simulator (eMAS) and the High Spectral Resolution Lidar 2 (HSRL2) that collected simultaneous and collocated measurements with the P-3 during several coordinated flights. During the 2016 deployment, the P-3 completed 14 science flights in total, 5 of which were collocated with the ER-2 and 9 of which included radiation-specific sampling maneuvers. Although the ER-2 did not participate in the 2017 deployment, the P-3 payload remained nearly the same except for the addition of HSRL-2 that had been deployed on the ER-2 during the 2016 campaign. Therefore, we focus on utilizing measurements taken from the P-3, which conducted 12 science flights in total, with 5 flights dedicated to radiation-specific studies in 2017. In this study, we primarily use measurements taken by SSFR, 4STAR, and HSRL-2 to investigate two cases, 20 September 2016 and 13 August 2017, which met specific requirements such as varying scene albedos and large aerosol loading. A companion paper will present more generalized results.

\subsection{SSFR and ALP}

The SSFR (Pilewskie et al., 2003; Schmidt and Pilewskie, 2012) is comprised of two pairs of spectrometers. Each pair consists of one spectrometer that is sensitive over the nearultraviolet, visible and very near-infrared wavelength range, and another that is sensitive in the shortwave infrared wavelength range. The spectra are joined at $940 \mathrm{~nm}$ to provide a full spectral range from 350 to $2100 \mathrm{~nm}$. The SSFR measures downward spectral irradiance $\left(F_{\lambda}^{\downarrow}\right)$ from a zenith light collector mounted on a stabilizing platform on the upper fuselage and upward spectral irradiance $\left(F_{\lambda}^{\uparrow}\right)$ from a nadir light collector fix-mounted to the aircraft. The externally mounted light collectors are connected by fiber optic cables to the spectrometer, which resides in the aircraft cabin along with the data acquisition unit. The SSFR was radiometrically calibrated with a NIST-traceable $1000 \mathrm{~W}$ lamp light source before and after each deployment, and relative calibration changes throughout the field campaign were monitored with a portable field standard. The light collectors consist of an integrating sphere with a circular aperture on top. They weigh the incoming radiance according to an angular response close to the cosine of the incidence angle. These light collectors have been improved over time (Kindel, 2010) to minimize the dependence on the azimuth angle of the incident radiance. However, the dependence on the polar angle, termed the cosine response, still requires careful characterization in the laboratory before and after the deployment. After applying all corrections, the uncertainty of the SSFR measurements is $3 \%-5 \%$ across the spectral range for both zenith and nadir irradiance. More importantly for this study, the precision is $0.5 \%-1.0 \%$.

The zenith light collector of SSFR was kept horizontally aligned by counteracting the variable aircraft attitude with an Active Leveling Platform (ALP), which was developed at CU Boulder for the NASA C-130 aircraft (Smith et al., 2017) and later rebuilt for the P-3, specifically for ORACLES. ALP relies on aircraft attitude information from a dedicated inertial navigation system (INS) that monitors the aircraft attitude, specifically the pitch and roll angles. This information is sent to a real-time controller, which additionally has the ability to instead ingest data from the aircraft INS. The controller drives the two actuators of a two-axis tip-tilt stage: one axis for aircraft roll movements and one for aircraft pitch movements. As the attitude angle changes, the tip-tilt stage adjusts accordingly to maintain the SSFR at the horizontal level position within approximately $0.2^{\circ}$. The nadir light collector was not actively leveled since the horizontal cloud variability introduces much more variability into the signal than any attitude changes. The upwelling irradiance is also less sensitive to pitch and roll angles than the downwelling irradiance.

For fix-mounted zenith light collectors, not only will the downward irradiance be referenced to an incorrect zenith due to the polar angle of incident light referenced to the aircraft horizon rather than true horizontal, but radiation from the lower hemisphere will also contaminate the zenith irradiance measurements if the receiving plane is not properly aligned with the horizon. This is especially problematic over bright surfaces such as snow, ice, or clouds. For ORACLES, it was important to sample the dependence of the downwelling irradiance on the aerosol conditions above. Since the aerosol-induced irradiance changes are small compared to the reflection by clouds, even minor contamination from the lower hemisphere could cause a bias in the signal. Such biases cannot be corrected in post-processing because common correction schemes assume that no radiation originates in the lower hemisphere (Bucholtz et al., 2008). ALP alleviates these problems and enables the collection of irradiance data during spiral measurements as long as pitch and roll stay within the ALP operating range of $6^{\circ}$. For the reasons mentioned above, spiral data have traditionally not been useful for radiation science. In this study, they turn out to be the key for achieving our stated goals.

\subsection{STAR, HSRL-2, and EMAS}

The 4STAR instrument provides direct-beam measurements of AOD above the aircraft at hundreds of wavelengths ranging from 350 to $1650 \mathrm{~nm}$, with a subset of 24 wavelengths 
available in the main ORACLES data archive (ORACLES Science Team, 2017a, b, 2019). The instrument is calibrated before and after each deployment using the Langley plot technique (Schmid and Wehrli, 1995); in addition, corrections for non-uniform azimuthal dependence of the transmission of the optical fiber path were assessed after each flight calibration (Dunagan et al., 2013) and corrected for in post-processing, resulting in an average AOD uncertainty of 0.011 at $500 \mathrm{~nm}$ (LeBlanc et al., 2019). 4STAR also provides other quantities, for example, column water vapor and trace gas retrievals, which are not used here. HSRL-2 is a downward-pointing lidar that provides vertical profiles of aerosol backscatter and depolarization at 355, 532, and $1064 \mathrm{~nm}$ wavelengths. Aerosol extinction is measured at 355 and $532 \mathrm{~nm}$ wavelengths (Hair et al., 2008; Burton et al., 2018). When the ER-2 was collocated with the P-3; imagery from the eMAS multispectral imager (King et al., 1996; Ellis et al., 2011) provided scene context.

\subsection{Methods of sampling: radiation walls and spirals}

There are two ways to determine aerosol-intensive optical properties from irradiance and AOD. An algorithm by Schmidt et al. (2010a) uses nadir and zenith irradiance pairs above and below a layer to retrieve SSA, $g$, and the surface albedo. A different algorithm, by Bergstrom et al. (2010), first derives the layer absorption and scene albedo from the irradiance pairs above and below the layer and then infers SSA, assuming a fixed value for $g$. Both methods were applied to clear sky and require irradiance measurements above and below a layer along with the associated AOD, which are most often obtained from individual points along the upper or lower leg of a "radiation wall" as shown in Fig. 1.

The intent of the wall is to obtain scene albedo, layer absorption, or transmittance by bracketing the aerosol layer above and below when flying at multiple altitudes along a track of about $100 \mathrm{~km}$ length. When only one aircraft is available, it samples the required legs sequentially, taking over an hour to complete. In clear sky, an aerosol layer will likely not change substantially during this time. However, in cloudy skies such as those encountered during ORACLES, the time lag between sequential sampling of the upper and lower legs is large enough that the cloud field is likely to change. Figure 1 illustrates the sampling for only two altitudes: at the bottom of the layer (BOL) and at the top of the layer (TOL) of interest. In the case of ORACLES, the BOL leg is located just below the aerosol layer and just above the cloud layer, where the column AOD and scene albedo are measured. The TOL leg is above the aerosol layer and the cloud, from which HSRL-2 measures profiles of extinction. Many other legs, for example below and within the cloud, and within the aerosol layer, were typically flown in addition to the BOL and TOL legs.

The net irradiance $\left(F_{\lambda}^{\text {net }}\right)$ at any level is the difference between the downwelling and upwelling irradiance. The ab-

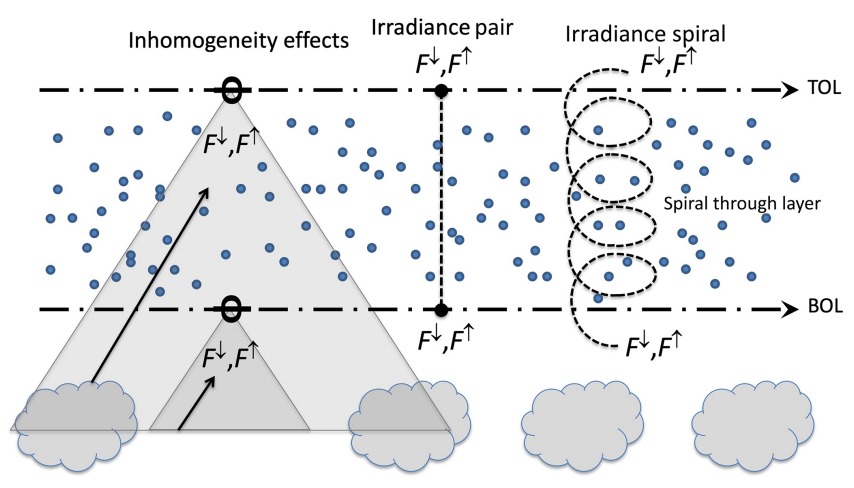

Figure 1. Schematic of a radiation wall, radiation spiral, and the appearance of horizontal flux divergence $\left(H_{\lambda}\right)$ in SSFR measurements. During a radiation wall, SSFR measures upwelling and downwelling irradiance along the top of layer leg (TOL) and bottom of layer (BOL) leg, which are collocated in space but not in time. During the radiation spiral, SSFR measures upwelling and downwelling irradiance throughout the entire aerosol layer. The left-hand side of the figure illustrates an example of how non-zero $H_{\lambda}$ arises in SSFR measurements under certain cloud conditions. The gray triangles figuratively represent the viewing geometry of SSFR at the TOL and BOL. Ignoring any change in clouds over time, the TOL SSFR-measured irradiances include contributions from a larger area than at the BOL. Under inhomogeneous conditions, the TOL and BOL SSFR measurements contain differing cloud scenes; in our illustration, the BOL measurement has little to no signal contribution from clouds, whereas the TOL measurement has a large contribution of the signal from clouds. The upwelling irradiance at the TOL would therefore be larger (smaller net irradiance) than at the BOL (larger net irradiance) due to the bright clouds.

sorption $A_{\lambda}$ of a layer can be determined from the difference of the net irradiance at the upper and lower boundaries (the vertical component $V_{\lambda}$ of the flux divergence) if the horizontal flux divergence of radiation $H_{\lambda}$ is negligible $\left(\left|H_{\lambda}\right|<<\left|V_{\lambda}\right|\right)$. Under horizontally homogeneous conditions, we assume $A_{\lambda}=V_{\lambda}$, which is usually the case, giving

$$
\begin{aligned}
A_{\lambda} & =V_{\lambda}=\frac{\left(F_{\lambda, \text { tol }}^{\text {net }}-F_{\lambda, \text { bol }}^{\text {net }}\right)}{F_{\lambda, \text { tol }}^{\downarrow}} \\
& =\frac{\left[\left(F_{\lambda, \text { tol }}^{\downarrow}-F_{\lambda, \text { tol }}^{\uparrow}\right)-\left(F_{\lambda, \text { bol }}^{\downarrow}-F_{\lambda, \text { bol }}^{\uparrow}\right)\right]}{F_{\lambda, \text { tol }}^{\downarrow}},
\end{aligned}
$$

where $A_{\lambda}$ and $V_{\lambda}$ have been normalized by the incident irradiance at the top of the layer $\left(F_{\lambda, \text { tol }}^{\downarrow}\right)$.

Under partially cloudy conditions,

$A_{\lambda}=V_{\lambda}-H_{\lambda}$

Schmidt et al. (2010b) found that $H_{\lambda}$ of a cloud layer is not negligible and can attain a magnitude comparable to $A_{\lambda}$ itself. Song et al. (2016) described the physical mechanism and spectral dependence of $H_{\lambda}$, which was determined by 
bracketing the cloud layer with irradiance measurements. For ORACLES, the aerosol above clouds, rather than the cloud itself, constitutes the layer of interest, but Fig. 1 illustrates how non-zero values of $H_{\lambda}$ may arise under inhomogeneous conditions. The aerosol retrievals are only accurate if $\left|H_{\lambda}\right|<<\left|V_{\lambda}\right|$, which ensures that Eq. (1a) holds. The data analysis showed that this condition was rarely met for wall measurements, but more often during spiral measurements (Sect. 3.1).

The radiation spiral, shown in Fig. 2 and illustrated conceptually in Fig. 1, provides multiple irradiance and AOD samples throughout the layer. Such a sampling pattern provides irradiance measurements at four headings throughout the column at a high vertical resolution without increasing the duration of the profile because the aircraft keeps descending or ascending during the straight segments, typically at 1000 feet (approximately $305 \mathrm{~m}$ ) per minute. During ORACLES, spirals were on average completed over the course of 10-20 min, depending on the vertical extent of the aerosol layer. Since typical roll angles during turns were $15-30^{\circ}$, exceeding the operating range of ALP, the spirals include short, straight segments of 20-30 s duration every $90^{\circ}$ heading change. The small pitch and roll values during the straight segments can be corrected for in real time by the ALP and lead to a rounded square-shaped pattern as shown in Fig. 2b and $d$ rather than a traditional, circular spiral pattern. SSFR acquires the irradiance profile over a minimal horizontal extent approximately $10 \mathrm{~km}$ in both latitude and longitude, reducing cloud and aerosol inhomogeneity effects, and over a much shorter time interval relative to the wall, maintaining correlation of measured irradiances throughout the spiral to the ambient cloud field. A circular spiral pattern with no straight segments with a roll angle under the roll limit would cover too large an extent, and the benefits of the square spiral pattern would be lost. Moreover, the four heading angles allow biases from mechanical mounting offsets of ALP or reflections and obscuration by the aircraft structure to be diagnosed. Acquiring a large number of samples over a relatively limited horizontal extent also reduces the impact of cloud albedo variability on the nadir irradiance. The downside of the spiral sampling is that it does not capture the spatial variability of the scene albedo, which is assessed by the radiation wall. Therefore, in order to investigate any spatial relationships between radiative effects and albedo, spiral measurements must be used in conjunction with AOD and scene albedo measurements from the radiation wall where the albedo is defined as

albedo $_{\lambda}=\frac{F_{\lambda}^{\uparrow}}{F_{\lambda}^{\downarrow}}$.

\subsection{Case selection}

To characterize the connections between DARE, aerosol properties, and scene albedo, we chose to explore cases based on (a) the availability of measurements from both a radiation wall and a radiation spiral, (b) relatively high aerosol loadings above the cloud field, and (c) a range of measured albedos. The first case is 20 September 2016, where the spiral was located approximately 2.5 degrees of longitude off the coast near the Namibia/Angola border. The cloud field for this case was homogeneous; the albedo of the BOL leg of the radiation wall ranged from 0.39 to 0.59 at $501 \mathrm{~nm}$. The radiation spiral was located at the northern end of the BOL leg. The aerosol layer was geometrically and optically thick, with an AOD measured just above clouds during the spiral of 0.57 at $501 \mathrm{~nm}$. The ER-2 flew in coordination with the P-3, such that eMAS imagery is available for context. Figure $2 b$ shows an eMAS image overlaid with the flight track of the P-3 for the spiral flight pattern, along with the ER-2 flight track. The second case on 13 August 2017, located approximately 8 degrees of longitude off of the coast of northern Angola, was chosen because of the inhomogeneous cloud conditions encountered along the BOL leg of the radiation wall. We treat this leg of the radiation wall as two separate cases based on differing albedo ranges - the northern end of the wall, where the albedo values at $501 \mathrm{~nm}$ range from 0.06 to 0.39 , and the southern end of the wall, where the albedo at $501 \mathrm{~nm}$ ranges from 0.29 to 0.75 . The radiation spiral was located on the southernmost point, though we use the retrieval results for both the North case and South case DARE calculations. Fig. 2d shows the spiral flight path overlaid on visible imagery from SEVIRI (Spinning Enhanced Visible and Infrared Imager) onboard the geostationary Meteosat Second Generation (MSG) (Schmid, 2000). The aerosol layer was significantly thinner than that of 20 September 2016, with an AOD at $501 \mathrm{~nm}$ measured just above clouds during the spiral of 0.22 . Table 1 lists the important parameter ranges for both spirals: UTC, latitude, longitude, solar zenith angle (SZA) and albedo at cloud top. Table 2 lists these parameters for the BOL legs for each of the three cases.

\section{Methods}

Our method to derive DARE from the observations is done with minimal assumptions. The DARE calculation is directly tied to the measured irradiances above and below the aerosol layer, and the AOD measured below the layer, since SSA and $g$ by definition are consistent with these measurements. This differs from derivations from (a) in situ observations where the aerosol properties are de-coupled from the radiation fields and (b) remote sensing observations where SSA and $g$ are often prescribed based on an aerosol parameterization by type or region. By ensuring that SSA and $g$ are consistent with the irradiance measurements in our approach, such assumptions are minimized when deriving DARE. 

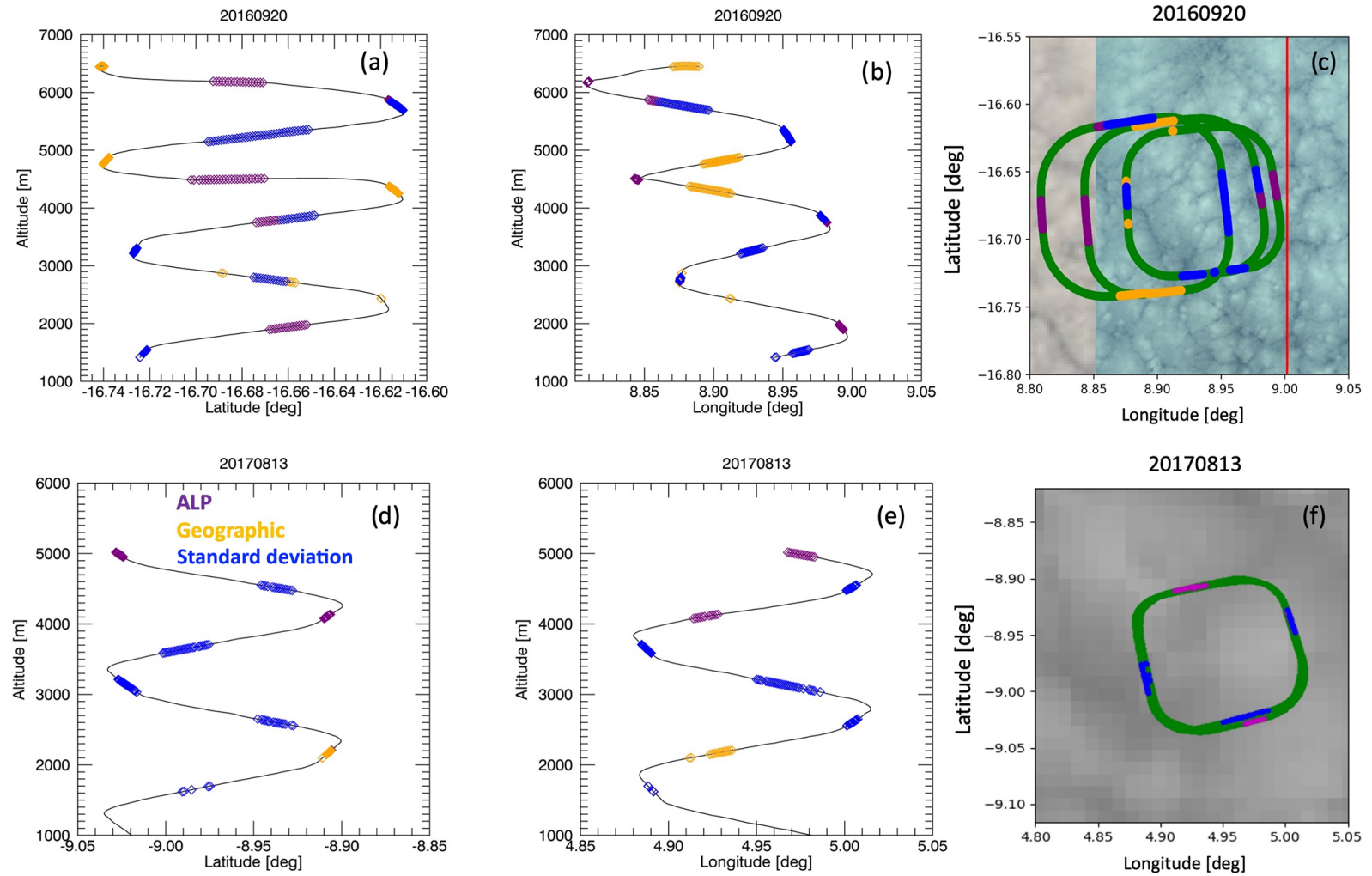

Figure 2. The (a) latitude vs. altitude and (b) longitude vs. altitude of altitude-filtered spiral data for 20 September 2016 . (c) The corresponding high-resolution eMAS imagery (blue) with lower resolution MODIS imagery (gray). Overlaid is the P-3 spiral flight track in green and ER-2 flight track in red. (d) The latitude vs. altitude and (e) longitude vs. altitude of altitude-filtered spiral data for 13 August 2017. (f) Corresponding SEVIRI imagery. For 20 September 2016, the altitude range is 1.4 to $6.5 \mathrm{~km}$, while for 13 August 2017 the altitude range is 1.7 to $5 \mathrm{~km}$. For all four figures, the purple color shows data that are within the limits of the ALP but do not pass the geographic or standard deviation filter. The orange color shows the data that have passed the geographic filter but do not pass the standard deviation filter. The blue points meet all of the requirements and are the data used within the linear fit to determine the TOL and BOL irradiances.

Table 2. Case description: BOL leg of the radiation wall.

\begin{tabular}{llll}
\hline Date & 20 September 2016 & 13 August 2017 North & 13 August 2017 South \\
\hline UTC & {$[11: 36,11: 42]$} & {$[12: 05,12: 20]$} & {$[11: 42,11: 54]$} \\
Latitude range & {$[-17.12,-16.97]$} & {$[-7.37,-6.29]$} & {$[-8.92,-8.06]$} \\
Longitude range & {$[8.99,9.00]$} & {$[4.31,4.53]$} & {$[4.69,4.88]$} \\
Albedo range [501 nm] & {$[0.39,0.59]$} & {$[0.06,0.39]$} & {$[0.29,0.75]$} \\
Solar zenith angle range & {$[18.5,18.8]$} & {$[22.1,22.3]$} & {$[22.7,23.5]$} \\
\hline
\end{tabular}

\subsection{Irradiance measurements: walls vs. spirals}

To derive accurate aerosol absorptance from SSFR measurements, irradiance pairs above and below the layer must first be obtained. For the radiation walls, the irradiance pairs are sampled from the BOL and TOL legs at coincident locations, neglecting cloud advection and cloud evolution during the elapsed time between the two. For spirals, the entire measurement profile from above cloud to above aerosol is used to establish a linear fit of the data from which irradiance pairs are derived, improving the sampling statistics compared to ra- diation wall irradiance pairs. Figure 3 illustrates SSFR measured nadir and zenith irradiances for aircraft attitudes within the operating range of ALP plotted against the 4STAR AOD at $532 \mathrm{~nm}$ as a vertical coordinate. Uncertainty bars are included for a subset of the measurements. Prior to fitting, all data are corrected to the SZA at the midpoint of the spiral to account for the minor change in solar position throughout the spiral:

$F_{\lambda}=F_{\lambda} \times \frac{\mu_{0}}{\mu}$ 

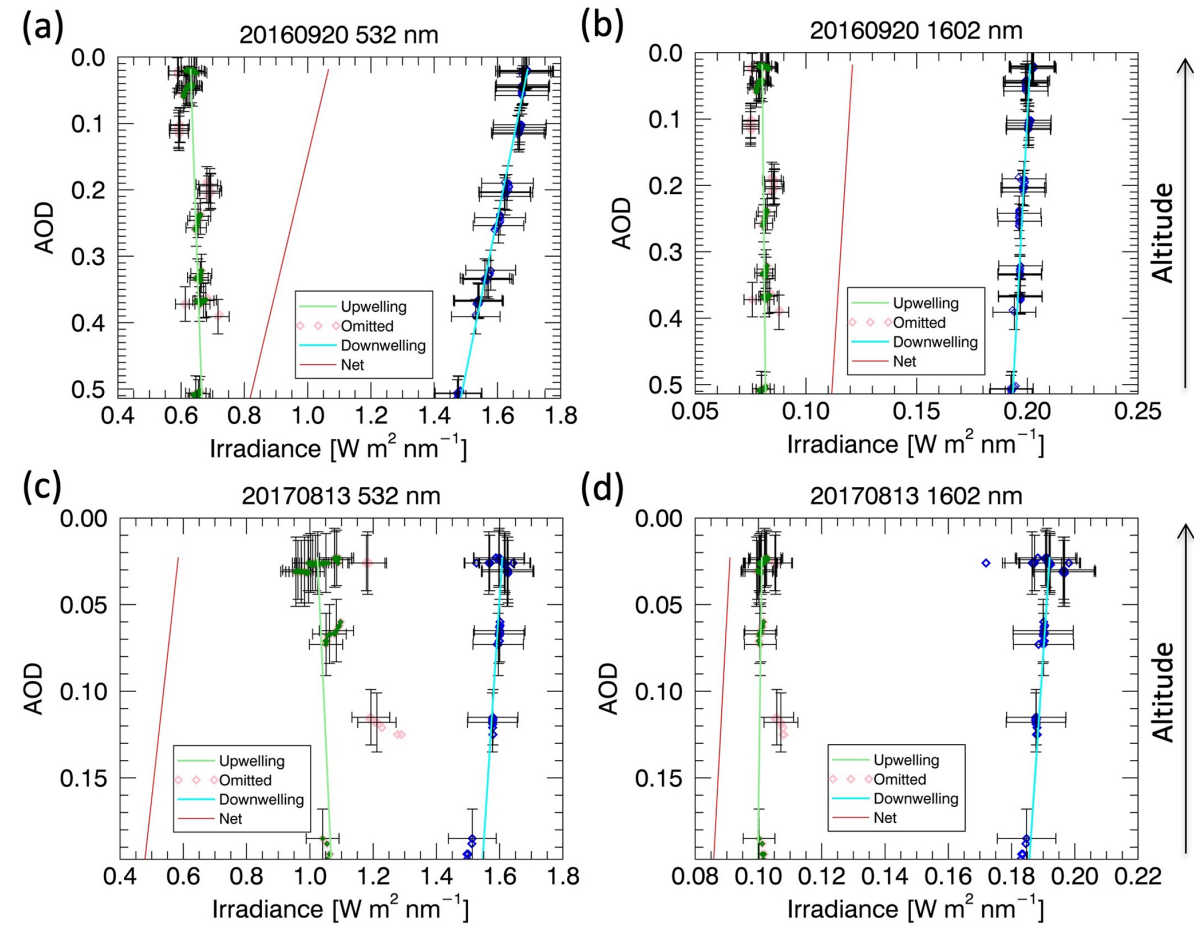

Figure 3. Examples of the filtering and extrapolation technique for 20 September 2016 (a) $532 \mathrm{~nm}$ and (b) $1602 \mathrm{~nm}$ and for 13 August 2017 radiation spirals at (c) $532 \mathrm{~nm}$ and (d) $1602 \mathrm{~nm}$. SSFR irradiance measurements are plotted against 4STAR above-aircraft AOD at $532 \mathrm{~nm}$ along with the associated measurement uncertainty. The omitted upwelling data (pink) did not pass the standard deviation or geographic filter and is not used for the calculation of the linear fit. All zenith measurements are included in the fit. At $1602 \mathrm{~nm}$, there is little to no aerosol absorption and the net irradiance is expected to be nearly constant with altitude. At $532 \mathrm{~nm}$ however, there is aerosol absorption and the net irradiance decreases with increasing AOD.

where $\mu=\cos (\mathrm{SZA})$ and $\mu_{0}$ is the value at the midpoint of the spiral.

To derive the BOL and TOL irradiances from the spiral using all the data, a linear regression is performed:

$F_{\lambda}^{\uparrow}=a_{\lambda}^{\uparrow}+b_{\lambda}^{\uparrow} \times \mathrm{AOD}_{532}$

$F_{\lambda}^{\downarrow}=a_{\lambda}^{\downarrow}+b_{\lambda}^{\downarrow} \times \mathrm{AOD}_{532}$

where $a_{\lambda}$ and $b_{\lambda}$ are the slope and intercept of the linear fit lines. The data points from the spiral are used collectively to establish the fit coefficients in Eqs. (4a) and (4b), which express the change in nadir and zenith irradiance with AOD. Subsequently, the irradiance values at BOL and TOL are determined from $\mathrm{AOD}_{532}^{\mathrm{max}}$, measured at the bottom of the layer, and $\mathrm{AOD}_{532}^{\mathrm{min}}$, measured at the TOL. This method is more robust than picking individual irradiance pairs from the wall because many more data points are used. The uncertainty of the fit coefficients is dominated by the variability of the data throughout the vertical profile, rather than by the radiometric uncertainty of the contributing data points, discussed in more detail in Sect. 3.4.

At a wavelength with small aerosol effects, such as $1.6 \mu \mathrm{m}$, shown in Fig. 3b, d, neither nadir nor zenith irradiance change significantly as the aircraft moves through the layer.
Any observed non-linearity or variability in the vertical profile at this wavelength can be ascribed to spurious measurement errors: for zenith, these could be due to reflections or obstructions by the aircraft or other factors causing a transient variability in the downwelling irradiance. For nadir, this is attributed to albedo changes in the cloud field below. By contrast, the irradiance at $532 \mathrm{~nm}$ (Fig. 3a, c) changes considerably throughout the vertical profile. The zenith irradiance decreases with decreasing altitude due to the increasing attenuation by the aerosol layer. The nadir irradiance shows the opposite behavior, decreasing with increasing altitude. By comparison, zenith and nadir irradiance would change in lock step for a purely scattering layer because the net irradiance remains constant in the absence of absorption.

\subsubsection{Data filtering}

To ensure that the aerosol signal is isolated from that of the variability of the underlying scene and that the data quality is sufficient to produce reasonable retrievals of SSA and $g$, a series of data filtering steps are applied.

1. Filter the data in altitude to encompass only the aerosol layer. This ensures a maximum change in the irradiance during the vertical profile with minimum signal varia- 
tions due to horizontal changes in the cloud field underneath (nadir) or any variability in the zenith signal unrelated to the aerosol layer. Figure 2a, c show the spiral data as a function of altitude, with color coding to highlight data that passes the altitude filter.

2. Select a subset of nadir data to focus on either predominantly clear or cloudy regions within the geographical footprint of the spiral. For the 20 September 2016 spiral, we focused on the cloudy pixels by selecting a longitude range of 8.86 to $8.98^{\circ} \mathrm{E}$ based on the eMAS imagery, illustrated in Fig. 2b, thereby eliminating regions that were substantially darker than the rest of the scene. The 13 August 2017 spiral did not require this filter because there were no clear regions distinguishable from cloudy regions (Fig. 2d).

3. Exclude data points where the nadir irradiance at $1.6 \mu \mathrm{m}$ exceeds 1 standard deviation of the mean. These points are rejected to minimize the impact of cloud spatial inhomogeneity on the upwelling signal. Fig. 3 indicates for each case the points that are included in the zenith and nadir linear fits and those that are outside of the standard deviation limit. The data points that are outside of the altitude and geographic filters are not shown. The aerosol loading on 13 August 2017 was significantly lower than on 20 September 2016, as well as the number of valid SSFR data points. This case was specifically chosen to explore the feasibility and sensitivity of the retrieval to variability in the upwelling irradiances and aerosol loading.

\subsubsection{Horizontal flux divergence}

Having obtained irradiance pairs from the wall or the spiral, the next step is to ensure that $\left|H_{\lambda}\right| \ll\left|V_{\lambda}\right|$ to minimize the impact of horizontal flux divergence in the subsequent retrieval of aerosol-intensive optical properties. At long wavelengths, $H_{\lambda}$ asymptotically approaches a constant value as described by Song et al. (2016), which we denote as $H_{\infty}$. At the same time, aerosol absorption decreases with increasing wavelength (and thus decreasing optical thickness). Figure $4 \mathrm{a}$ shows $V_{\lambda}$ plotted as a function of $\mathrm{AOD}_{\lambda}$ for 20 September 2016 and 13 August 2017. The intercept at $\mathrm{AOD}=0$ ( $A=0$ by definition $)$ determines $H_{\lambda}$ because any non-zero measurement of $V_{\lambda}$ must originate from $H_{\lambda}$ in the absence of absorption. In the limit of $\lambda \rightarrow \infty$,

$\lim _{\mathrm{AOD}(\lambda) \rightarrow 0} V_{\lambda} \equiv H_{\infty}$

Thus, even though we do not determine $H_{\lambda}$ directly, $H_{\infty}$ is straightforward to obtain. Because of the findings of Song et al. (2016), $H_{\lambda}$ is zero for all wavelengths if $H_{\infty}$ is zero. Therefore, it is justified to apply Eq. (1) to estimate $A_{\lambda}$ only if $H_{\infty}=0$.
Table 3. (a) $H_{\infty}$ and select $i_{\lambda}$ values for the 20 September 2016 case. (b) $H_{\infty}$ and select $i_{\lambda}$ values for the 13 August 2017 case.

\begin{tabular}{lll}
\hline (a) & & \\
\hline 20160920 & Spiral & Wall (minimum, maximum) \\
\hline$H_{\infty}$ & 0.0112 & $-0.15,0.11$ \\
$i_{\lambda} 355 \mathrm{~nm}$ & 0.04 & $-0.45,0.46$ \\
$i_{\lambda} 532 \mathrm{~nm}$ & 0.08 & $-0.86,0.78$ \\
$i_{\lambda} 1650 \mathrm{~nm}$ & 0.55 & $-113.9,100.2$ \\
\hline (b) & & \\
\hline 20170813 & Spiral & Wall (minimum, maximum) \\
\hline$H_{\infty}$ & 0.0131 & South: $-0.65,0.06$ \\
& & North: $-0.83,-0.29$ \\
\hline$i_{\lambda} 355 \mathrm{~nm}$ & 0.08 & South: $-1.9,0.35$ \\
& & North: $-2.22,-1.35$ \\
\hline$i_{\lambda} 532 \mathrm{~nm}$ & 0.17 & South: $-5.4,0.59$ \\
& & North: $-5.43,-2.68$ \\
\hline$i_{\lambda} 1650 \mathrm{~nm}$ & 1.57 & South: $-726.4,3832.95$ \\
& & North: $-410.8,-4.94$ \\
\hline
\end{tabular}

Table $3 \mathrm{a}$ and $\mathrm{b}$ show that the calculated $H_{\infty}$ values for the filtered spiral data are near zero but significantly higher for the walls. For the 2016 case, $H_{\infty}=1.12 \%$ for the spiral and up to $15 \%$ for the irradiance samples from the wall. $H_{\infty}$ is larger for the 13 August 2017 spiral, about $1.3 \%$, which could be due to the larger scene inhomogeneity based on the available imagery. It makes sense that the wall measurements have larger values for $H_{\infty}$, mainly because the collocated pairs do not necessarily represent the irradiance of the same scene, considering the time difference between the BOL and TOL legs. In addition, the effective footprint of the nadir SSFR light collector (the circle from within which half of the signal originates) changes at different altitudes, which means that the horizontal extent of cloud that contributes to the sampled signal for the TOL leg is much greater than for the BOL leg. While this is also true for the spiral, the standard deviation filtering effectively separates the aerosol signal from that of changes in scene albedo, including those due to the changing footprint size of SSFR with altitude.

To quantify the horizontal variability in the flux field relative to the aerosol absorption, we introduce the inhomogeneity ratio

$i_{\lambda}=\frac{H_{\infty}}{V_{\lambda}-H_{\infty}}$.

The denominator approximates the true absorption, where the horizontal flux contribution to the observed $V_{\lambda}$ has been subtracted to yield $A_{\lambda}$ (though we have substituted $H_{\infty}$ for $\left.H_{\lambda}\right) . V_{\lambda}$ and $H_{\infty}$ are both measurable quantities, while $A_{\lambda}$ can only be inferred from $V_{\lambda}$ if $H_{\infty}$ is near zero. If $H_{\infty}$ is similar (or exceeds) in magnitude to $V_{\lambda}, H_{\lambda}$ will also 
(a)

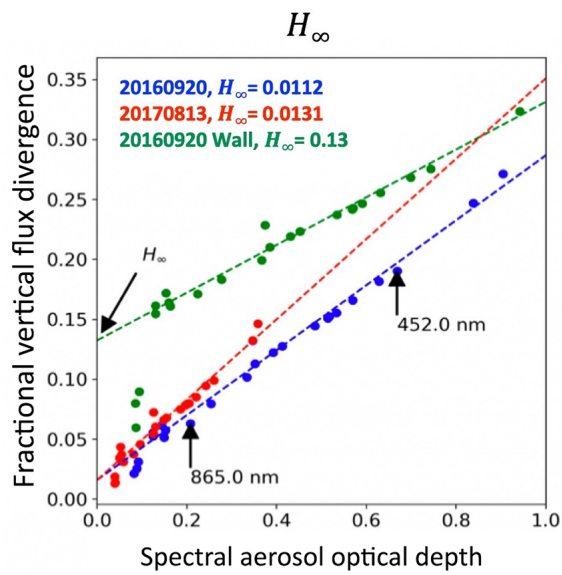

(b)

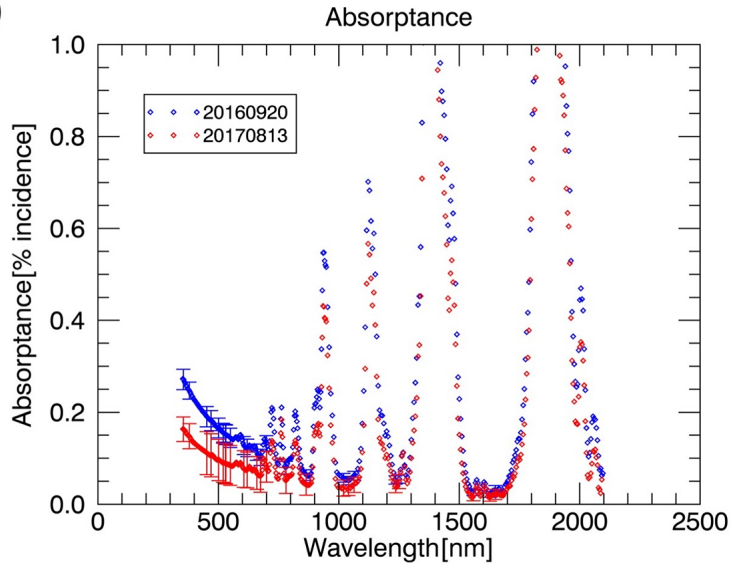

Figure 4. Examples of the method for determining $H_{\infty} . V_{\lambda}$ is shown as a function of $\mathrm{AOD}_{\lambda}$ for all $4 \mathrm{STAR}$ wavelengths for both cases (20160920 in blue; 20170813 in red) along with an example point from the 20160920 radiation wall. At long wavelengths, the horizontal flux divergence $H_{\lambda}$ asymptotes to a constant value $\left(H_{\infty}\right)$; a non-zero value indicates 3-D effects. Here we perform a linear fit between $\mathrm{AOD}_{\lambda \text {,max }}$ and $V_{\lambda}$, the vertical flux divergence, for all 4STAR wavelengths where $H_{\infty}$ is the $y$ intercept, thereby bypassing the necessity of determining $H_{\lambda}$ directly. Figure $4 \mathrm{~b}$ : the spiral derived for 20 September 2016 and 13 August 2017. Uncertainty estimates are shown as error bars at the 4STAR wavelengths.

be of similar magnitude, and we cannot determine $A_{\lambda}$ from $V_{\lambda}$. The spectral inhomogeneity metric provides an empirical method to determine when this occurs.

Table 4 summarizes the interpretation of $i_{\lambda}$ values, which can be either positive or negative due to the horizontal flux divergence; when $i_{\lambda}$ is positive, this indicates a divergence of radiation within the layer (apparent absorption), and when $i_{\lambda}$ is negative it indicates a convergence (apparent emission). We expect that as the wavelength becomes longer, the magnitude of $i_{\lambda}$ will also increase since the aerosol absorption is largest at the shortest wavelengths, while $H_{\lambda}$ is not strongly wavelength dependent. Table $3 \mathrm{a}$ and $\mathrm{b}$ list the $i_{\lambda}$ values at 355,532 , and $1650 \mathrm{~nm}$ for the spiral and, for illustration, the maximum and minimum $i_{\lambda}$ values from the radiation walls. Both spirals exhibit near-zero $i_{\lambda}$ values at 355 and $532 \mathrm{~nm}$, though the 13 August 2017 values are slightly closer to 1, in large part due to the lower aerosol loading, and the retrieval from 20 September 2016 is therefore more reliable than 13 August 2017. The maximum (minimum) $i_{\lambda}$ values for the radiation walls are larger (smaller) than the spiral values at all wavelengths. The specific $i_{\lambda}$ values for which performing an aerosol retrieval is minimally affected by $H_{\lambda}$ are subjective, and a follow-up paper will further develop and characterize the limits by investigating more cases from ORACLES.

Because of the high $H_{\infty}$ and $i_{\lambda}$ values, the wall measurements are not used to determine aerosol absorptance or for the SSA and $g$ derivation. Conversely, the near-zero $H_{\infty}$ values and low $i_{\lambda}$ values of the spirals allow us to substitute
Table 4. Interpretation of $i_{\lambda}$ relating to the relative magnitudes of $V_{\lambda} H_{\lambda}$.

\begin{tabular}{llll}
\hline$i_{\lambda}$ & \pm 1 & $<1>-1$ & $>1<-1$ \\
\hline $\begin{array}{l}\text { Relative } \\
\text { Magnitude }\end{array}$ & $V_{\lambda} \sim H_{\lambda}$ & $V_{\lambda}>H_{\lambda}$ & $V_{\lambda}<H_{\lambda}$ \\
$\begin{array}{l}\text { Successful aerosol } \\
\text { retrieval }\end{array}$ & Unlikely & Likely & Not possible \\
\hline
\end{tabular}

Eqs. (4a) and (4b) into Eq. (1), which simplifies to

$A_{\lambda}=\frac{\mathrm{AOD}_{532}^{\max } \times\left(b_{\lambda}^{\uparrow}-b_{\lambda}^{\downarrow}\right)}{a_{\lambda}^{\downarrow}}$.

The spiral-derived absorptance spectra for (a) 20 September 2016 and (b) 13 August 2017 are shown in Fig. 4b. The largest absorptance occurs in the water vapor bands of 1870 , 1380,1100 , and $940 \mathrm{~nm}$. In the relatively water-free spectral range, approximately $900 \mathrm{~nm}$ and shorter, the absorptance is dominated by aerosol absorption (except for a few water vapor bands with relatively low absorption, the oxygen A- and B-bands, the Chappuis ozone absorption band, and other trace gas absorption). The 4STAR AOD retrieval wavelengths specifically avoid the gas absorption features, although those that coincide with the Chappuis ozone absorption band and other trace gas absorption bands are unavoidable and are accounted for in the 4STAR retrieval (see the Appendix of LeBlanc et al., 2019).

The subsequent retrievals of SSA and $g$ use the individual upwelling and downwelling irradiances rather than the absorptance from the spiral profiles. Lacking other constraints, 
we assume that since $A_{\lambda}$ is unaffected by cloud inhomogeneity when $H_{\infty}$ is near zero, the same is true for the irradiances from which $V_{\lambda}$ is originally calculated. $H_{\infty}$ and $i_{\lambda}$ serve as metrics to assess the suitability of data for the aerosol retrieval.

\subsection{SSA retrieval}

The retrieval of SSA and $g$ is done with publicly available one-dimensional (1-D) radiative transfer model (RTM) DISORT 2.0 (Stamnes et al., 2000), with SBDART for atmospheric molecular absorption (Ricchiazzi et al., 1998) along with the standard tropical atmosphere available within the libRadtran public library (Emde et al., 2016; http://www. libradtran.org, last access: 15 November 2019). In contrast to the algorithms by Pilewskie et al. (2003), Bergstrom et al. (2007), and Schmidt et al. (2010a), the aerosol layer is located over a variable cloud scene, but otherwise the principle is the same. This work is most similar to the algorithm introduced by Schmidt et al. (2010a), for which SSA and $g$ are retrieved simultaneously.

The RTM allows us to calculate upwelling and downwelling fluxes determined by inputs of the surface albedo and the aerosol properties of AOD, SSA, and the asymmetry parameter. The updated retrieval algorithm is based on the comparison between the calculated fluxes and the SSFRmeasured fluxes. Spectral albedo from SSFR and AOD from 4STAR are used as inputs, which leaves SSA and $g$ as the free retrieval parameters. For 20 September 2016, the SZA within the RTM is set to 21.0 and the albedo at $501 \mathrm{~nm}$ is 0.45, while for 13 August 2017, the SZA is set to 33.5 and the albedo at $501 \mathrm{~nm}$ is 0.70 . Since the cloud albedo is directly measured, cloud properties such as COT and effective radius are not required - an advantage when compared to the associated remote sensing bias when obtaining it from spaceborne imagery (Chen et al., 2019).

The first step in the retrieval is to condition the 4STAR AOD so that the column-integrated AOD profile decreases monotonically with altitude. Because 4STAR samples horizontal as well as vertical variability throughout the spiral, the AOD profile can sometimes deviate from a strictly monotonic decrease, which cannot be ingested by the RTM. We alleviate this problem by smoothing the AOD profile with a polynomial to eliminate minor deviations from monotonic behavior. For instances when the derived extinction becomes negative, we set the value to 0 . Figure 5 a (20 September 2016) and b (13 August 2017) visualize the original AOD profile and the corresponding polynomial. The unique altitude to AOD relationship is used to derive the extinction profile, also shown in Fig. 5a, b. Above the aerosol layer, any remaining AOD measured by 4STAR is assigned to a layer extending to $15000 \mathrm{~m}$ (a top altitude chosen somewhat arbitrarily lacking the knowledge of the correct height distribution of the residual AOD). While a direct comparison of 4STAR above-cloud AOD (LeBlanc et al., 2019) and HSRL- derived column-integrated AOD for $532 \mathrm{~nm}$ is possible, it is not straightforward due to the different viewing geometries of the instruments and is not done here.

In the second step of the retrieval, the RTM calculates the upwelling and downwelling irradiance profiles for each given $\{$ SSA,$g\}$ pair within a broad, physically reasonable range. The modeled downwelling irradiance profile is rescaled such that the model results at the TOL are consistent with the measured downwelling irradiance. The scaling factor effectively allows for inaccurate values in the extraterrestrial solar flux (Kurucz, 1992), for differences in atmospheric constituents, such as aerosols above the aircraft's top altitude, or for absorbing gases not accounted for using the standard atmospheric profile. It is typically close to 1 . At the BOL, the measured upwelling irradiances are also rescaled such that the model albedo is consistent with measured albedo. If the calibration for the upwelling and downwelling irradiance is consistent, the scale factors should be the same. Therefore, any retrieval with differing nadir and zenith scale factors is flagged as failed.

The third step of the retrieval determines the most probable pair of $\{$ SSA, $g\}$ and calculates the uncertainty. For each $\{$ SSA, $g\}$ pair calculation, every SSFR data point in the profile is assigned a probability according to the difference between the calculation and the measurement. The probability of $\{$ SSA, $g$ \} given the SSFR observations is determined from the Gaussian distribution that represents the measurement uncertainty. This is illustrated in Fig. 6a. The probability of that pair given the observations is determined by multiplying the individual probabilities within the profile. The $\{$ SSA, $g\}$ pair with the highest probability value is reported as the retrieval result. The $\{$ SSA, $g$ \} pair probabilities are shown as a 2-D probability density function (PDF) in Fig. 6b, where the error bars show the $1 \sigma$ uncertainty for SSA and $g$ separately, determined by the respective marginal (1-D) PDFs. Since only the SSFR uncertainty is considered within the retrieval, the 4STAR uncertainty is treated separately by performing the retrieval three times: (1) for the nominal AOD, (2) for the nominal AOD - range of uncertainty, (3) for the nominal AOD + range of uncertainty. Figure $6 \mathrm{~b}$ shows an example retrieval at $380 \mathrm{~nm}$ for the three retrievals. Finally, the retrieved spectra of 4STAR wavelengths between 355 and $660 \mathrm{~nm}$ of SSA and $g$ are reported, with a range of uncertainty that encompasses the three separate retrievals.

Currently, the retrieval is performed for each wavelength individually, and no spectral smoothness constraints are applied. This is an important difference compared to other methods such as the AERONET inversion method that retrieves aerosol size distributions and the real and imaginary parts of the index of refraction for various size modes (Dubovik and King, 2000).

The retrieval also allows us to calculate the absorption Ångström exponent (AAE) from the absorbing aerosol optical depth (AAOD) which, like SSA, quantifies the radiative effects and optical properties of absorbing aerosols 
(a)

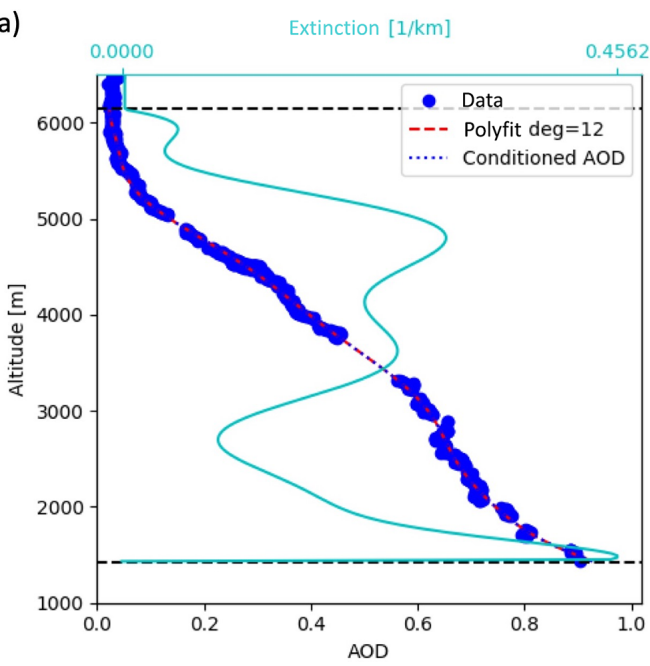

(b)

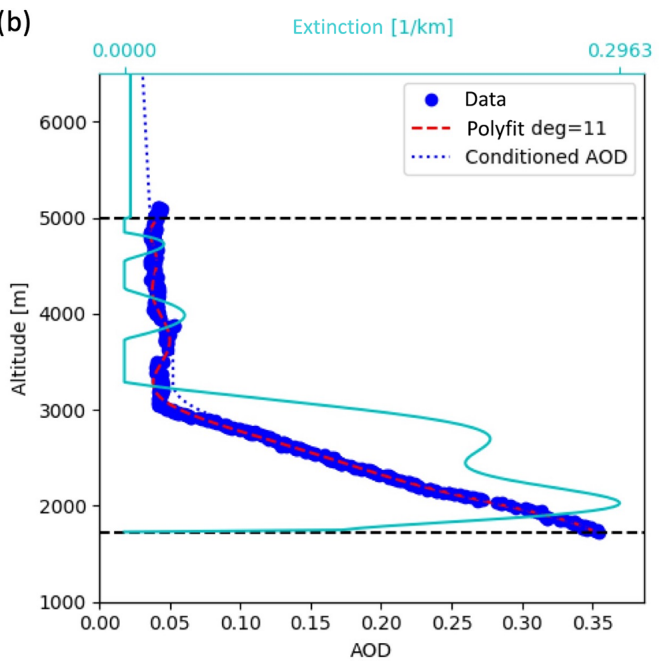

Figure 5. The 4STAR homogenized AOD profile for $355 \mathrm{~nm}$ is shown as blue circles for (a) 20 September 2016 and (b) 13 August 2017. The polynomial is shown as a red dashed line, and the derived extinction profile is shown as a teal line. The two black dashed lines indicate the BOL and TOL; any AOD measured above the top of the layer is distributed within a layer up to $15000 \mathrm{~m}$, well above the spiral altitudes.

(a)

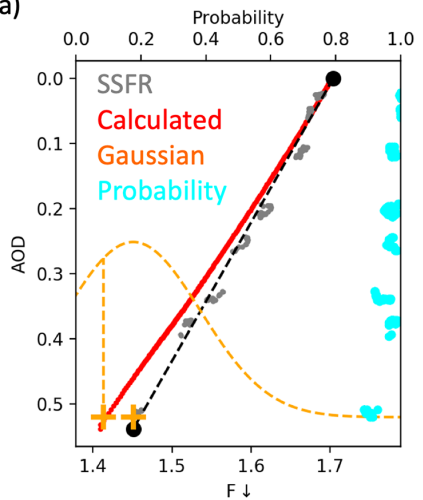

(b)

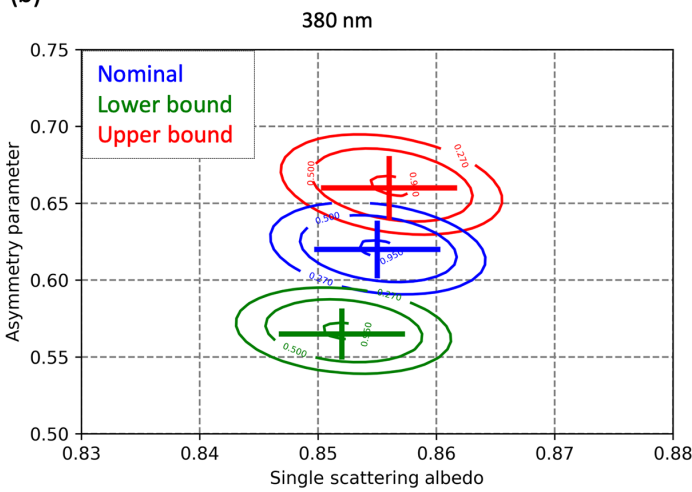

Figure 6. (a) This figure shows measurements of downwelling irradiance (gray) along with a calculated profile (red) for one pair of SSA and $g$. The probability of this pair, given the measurements, is obtained by considering the measurement uncertainty range (represented as a Gaussian, yellow) for the individual data points and assigning a probability (cyan, upper axis) to each data point according to the difference between the calculation and the measurement. The individual probabilities are then multiplied throughout the profile and constitute the probability of the $\{$ SSA, $g\}$ pair given the observations. (b) shows these probabilities as a function of SSA and $g$, calculated for the nominal 4STAR AOD (blue) and for the upper (red) and lower (blue) bounds of the reported uncertainty range. The ellipses represent confidence levels of $27 \%, 50 \%$, and $95 \%$.

(Pilewskie et al., 2003; Bergstrom et al., 2010). The AAE and AAOD are determined as follows:

$\mathrm{AAOD}=(1-\mathrm{SSA}) \times \mathrm{AOD}$

$\mathrm{AAOD}=\mathrm{AAOD}_{500} \times\left(\frac{\lambda}{\lambda_{500}}\right)^{-\mathrm{AAE}}$.

We compare the AAE and SSA results from our retrieval to in situ measurements from a three-wavelength nephelometer (TSI 3563) and a three-wavelength particle soot absorption photometer (PSAP) (Radiance Research). The PSAP provides AAE, while the combination of scattering from the nephelometer and absorption from the PSAP provides
SSA. Average values of SSA are weighted by the extinction, specifically to obtain a column value of SSA from the spiral profiles.

\subsection{DARE and critical albedo}

We calculate the DARE at the TOL and BOL as the difference between the net irradiance with and without the aerosol layer:

$\operatorname{DARE}_{\lambda}=F_{\lambda, \text { aer }}^{\text {net }}-F_{\lambda, \text { no aer }}^{\text {net }}$.

The DARE calculations are performed with the aerosolintensive properties (SSA and $g$ ) from the spiral profiles and 
with the albedo as measured by SSFR and AOD from 4STAR from a BOL leg. HSRL-2 extinction profiles are taken from the TOL leg (2017) or from the collocated ER-2 leg (2016) to capture any variability within the aerosol encountered along the wall.

Combining vertical and horizontal sampling in this way is predicated on the assumption that the aerosol-intensive properties do not change along the BOL leg, whereas albedo and AOD are expected to vary. This is a reasonable assumption as long as the legs do not cross an air-mass boundary; in situ measurements show that along the BOL leg on 20 September 2016, the SSA at $530 \mathrm{~nm}$ ranges from 0.80 to $0.86(0.83 \pm 0.01$, average \pm standard deviation $)$. During this same time, the PSAP instrument shows that the AAE ranges from 1.71 to $2.02(1.87 \pm 0.05)$. From a radiation wall leg within the aerosol layer (12:35-12:47 UTC), the SSA ranges from 0.84 to $0.87(0.85 \pm 0.004)$. The AAE ranges from 1.71 to 1.99 for this time $(1.84 \pm 0.04)$. On 13 August (both the northern and southern sections), the SSA from the BOL leg ranges from 0.84 to $0.93(0.87 \pm 0.02)$, while the AAE ranges from 0.97 to $2.1(1.6 \pm 0.3)$. Within the aerosol layer (14:08$14: 18$ UTC), the SSA ranges from 0.88 to $0.90(0.89 \pm 0.003)$ and the AAE ranges from 1.80 to 2.16 (1.92 \pm 0.07 ) (Dobracki et al., 2019). In light of the AAE and SSA ranges in the in situ measurements, it does not appear that the legs crossed an air-mass boundary, but the aerosol-intensive properties also cannot be considered constant. However, the measured variability in the in situ SSA is captured by the standard deviation of its retrieved counterpart and is thus propagated into an uncertainty for DARE.

Since the spectral information is available, we choose to calculate DARE spectrally $(350-660 \mathrm{~nm})$ as a percentage of the incoming radiation rather than as broadband values commonly reported. Within the RTM, the SZA is fixed to the mean value of the above cloud leg; for consistency, SSFR measurements are corrected to this SZA following Eq. (3) (17.9 $9^{\circ}$ for 20 September $2016,22.1^{\circ}$ for the North case of 13 August 2017 , and $23.2^{\circ}$ for the South case of $13 \mathrm{Au}$ gust 2017). The albedo ranges for each case are presented in Table 2, and the aerosol-intensive properties used are presented in Fig. 7. Although 0 and 1 albedo values were not actually encountered, we include them in the RTM runs and calculate the DARE to investigate the behavior at the albedo limits. The relationship between DARE and SSFR-measured albedo is nearly linear; therefore, we fit a line to the 1-D calculations to find the $x$ intercept, which is the critical albedo.

To estimate the total DARE uncertainty, we combine the errors of the individual components:

$$
\delta \mathrm{DARE}_{\text {total }}=\frac{\sqrt{\left(\delta \mathrm{DARE}_{g}\right)^{2}+\left(\delta \mathrm{DARE}_{\mathrm{albedo}}\right)^{2}}}{+\left(\delta \mathrm{DARE}_{\mathrm{AOD}}\right)^{2}+\left(\delta \mathrm{DARE}_{\mathrm{SSA}}\right)^{2}}
$$

where each parameter uncertainty is calculated as

$$
\begin{aligned}
\delta \mathrm{DARE}_{g}= & \frac{\left|\mathrm{DARE}_{g+\delta \mathrm{g}}-\mathrm{DARE}_{g-\delta g}\right|}{2}, \\
\delta \mathrm{DARE}_{\text {albedo }}= & \frac{\left|\mathrm{DARE}_{\text {albedo }+\delta \text { albedo }}-\mathrm{DARE}_{\text {albedo }-\delta \text { albedo }}\right|}{2}, \\
\delta \mathrm{DARE}_{\mathrm{AOD}} & =\frac{\left|\mathrm{DARE}_{\mathrm{AOD}+\delta \mathrm{AOD}}-\mathrm{DARE}_{\mathrm{AOD}-\delta \mathrm{AOD}}\right|}{2}, \\
\delta \mathrm{DARE}_{\mathrm{SSA}} & =\frac{\left|\mathrm{DARE}_{\mathrm{SSA}+\delta \mathrm{SSA}}-\mathrm{DARE}_{\mathrm{SSA}-\delta \mathrm{SSA}}\right|}{2} .
\end{aligned}
$$

The uncertainties of $g$ and SSA are obtained from their retrieval, and the AOD uncertainty is the measurement uncertainty. Since the albedo is a ratio of upwelling and downwelling irradiance, calibrated using the same apparatus, the relative precision of the measurements to each other drives the uncertainty rather than through error propagation of each calibrated accuracy. The albedo uncertainty is estimated to be approximately $1 \%$.

This method assumes all four individual uncertainties are uncorrelated and most likely overestimates the DARE uncertainty.

\section{Results and discussion}

\subsection{Aerosol properties}

The SSA spectra from 355 to $660 \mathrm{~nm}$ retrieved from the radiation spirals for each case are shown in Fig. 7a, b, and Table 5 presents a comparison between SSFR-derived SSA and AAE with past results and in situ measurements from ORACLES. The 20 September 2016 case can be considered spectrally flat with a minimum SSA value of $0.83( \pm 0.02)$ at $660 \mathrm{~nm}$ and a maximum SSA value of $0.86( \pm 0.01)$ at $380 \mathrm{~nm}$. The 13 August 2017 case shows a spectrally flat SSA with 0.83 $( \pm 0.04)$ at $355 \mathrm{~nm}$ and $0.82( \pm 0.07)$ at $660 \mathrm{~nm}$. Compared to the SAFARI 2000 campaign results shown in Russell et al. (2010), the results from the two ORACLES cases are slightly lower, 0.87 at $501 \mathrm{~nm}$ compared to $0.85( \pm 0.01)$ (20 September 2016) and $0.82( \pm 0.05)$ (13 August 2017) at $501 \mathrm{~nm}$, although the values are similar to those presented in Giles et al. (2012) for AERONET sites that experienced smoke aerosol events (Giles et al., 2002; Eck et al., 2003a, b). In situ measurements of the extinction weighted SSA from the spiral profiles and are shown in Fig. 7a, b. At $530 \mathrm{~nm}$, the 20 September 2016 spiral had an average SSA of 0.86 with a standard deviation of 0.03 , while the 13 August 2017 spiral had an average SSA of 0.88 with a standard deviation of 0.01 . Table 4 presents a comparison at 500 and $530 \mathrm{~nm}$ between SSFR-derived SSA and AAE with past results and in situ measurements from ORACLES, and a detailed SSA inter-comparison can be found in Pistone et al. (2019).

Also included in Fig. 7a, b are the uncertainty estimates for each wavelength, shown as the smaller, blue error bars. The larger, black error bars illustrate what the uncertainty would 
Table 5. Comparison of ORACLES SSA and AAE values to Russell et al. (2010) SAFARI results. SSFR results include their estimated uncertainties; the in situ extinction-weighted averages include corresponding standard deviations.

\begin{tabular}{llllll}
\hline & $\begin{array}{l}\text { SSFR- } \\
20160920\end{array}$ & $\begin{array}{l}\text { SSFR- } \\
20170813\end{array}$ & $\begin{array}{l}\text { In Situ- } \\
20160920\end{array}$ & $\begin{array}{l}\text { In Situ- } \\
20170813\end{array}$ & $\begin{array}{l}\text { Russell et } \\
\text { al. (2002) } \\
\text { - SAFARI 2000 } \\
\text { campaign }\end{array}$ \\
& & & & \\
\hline SSA-500 nm & $0.85 \pm 0.01$ & $0.82 \pm 0.05$ & & & 0.87 \\
SSA-530 nm & $0.84 \pm 0.01$ & $0.81 \pm 0.05$ & $0.86 \pm 0.03$ & $0.88 \pm 0.01$ & \\
AAE & $1.29(355-$ & $1.44(355-$ & $1.79 \pm 0.15(470-$ & $1.71 \pm 0.07(470-$ & $1.45(325-$ \\
& $660 \mathrm{~nm})$ & $660 \mathrm{~nm})$ & $660 \mathrm{~nm})$ & $660 \mathrm{~nm})$ & $1000 \mathrm{~nm})$ \\
\hline
\end{tabular}

(a)

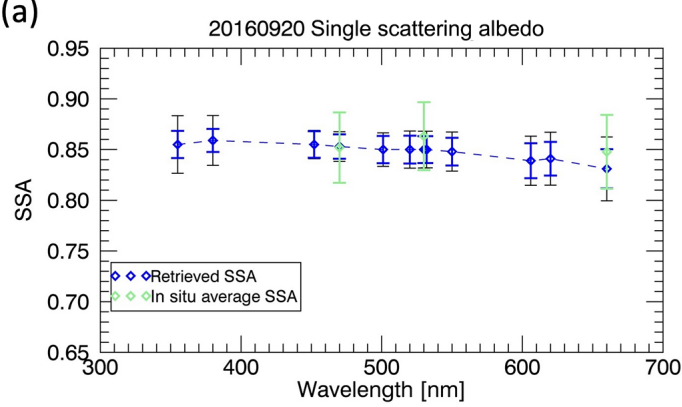

(c)

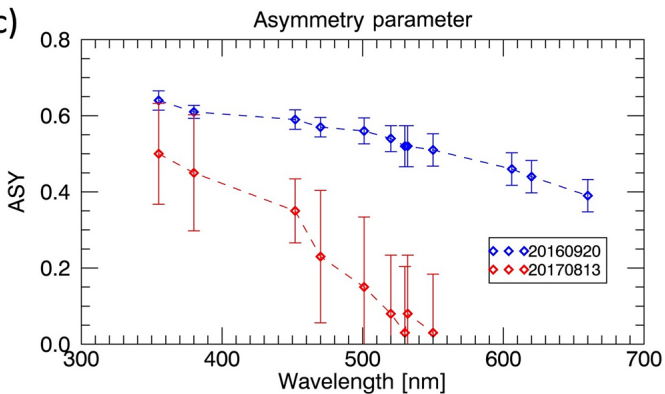

(b)
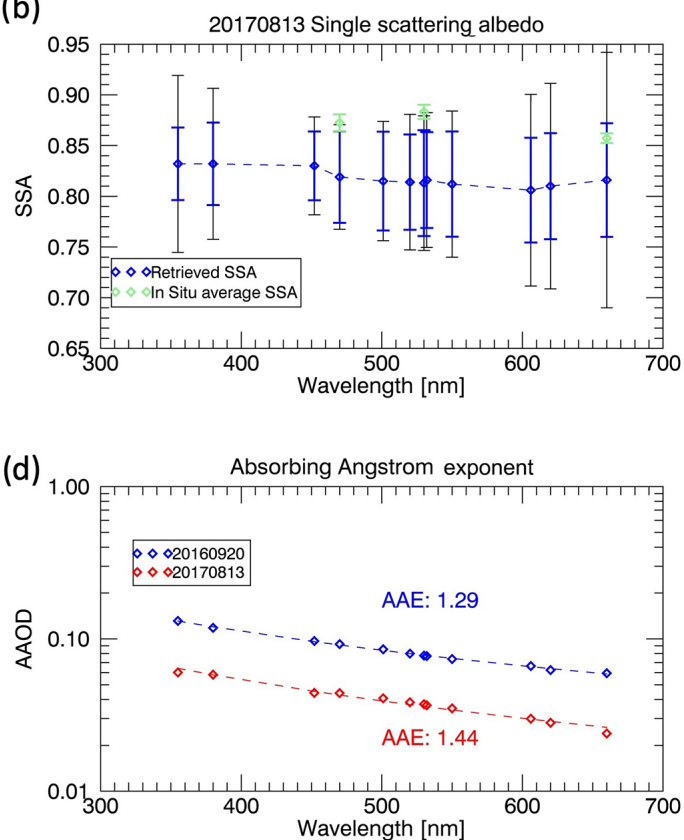

Figure 7. Spiral derived SSA values for (a) 20 September 2016 and (b) 13 August 2017 with associated error bars. The smaller error bars in blue are the spiral uncertainty estimates; the larger error bars (black) are the uncertainties associated with the irradiance pair method. The green symbols show the in situ extinction-weighted average SSA throughout the spiral profile with standard deviations shown as error bars. (c) The retrieved asymmetry parameter with associated error bars for both cases. (d) The AAOD spectra from which the absorbing Ångström exponent is derived for both cases.

be if we had derived the SSA using irradiance pairs rather than from the whole profile (i.e., if the spiral TOL and BOL values had been taken from a radiation wall). The uncertainty derivation for the radiation wall measurements requires the assumption that $H_{\lambda}=0$, though as we have shown, this is not the case and is described in detail in Appendix A. As can be seen in Fig. 7, the uncertainty from the walls is much larger than from the new spiral method and would be even larger if we included error due to $H_{\lambda}$.

Figure $7 \mathrm{c}$ shows the asymmetry parameter retrievals along with uncertainty estimates. The values $(0.45-0.65)$ for the 20 September 2016 case are within the range of other estimates for the region, although the spectrum falls off more rapidly than assumed by Meyer et al. (2013). The large un- certainties for the 13 August 2017 case show that even for moderate mid-visible AOD $(\sim 0.3)$, the information content with respect to this retrieval parameter is fairly low. Despite the limited information content in the SSFR stand-alone retrievals, there is some indication that the asymmetry parameter always falls off more rapidly than in previous assessments - with a value approaching zero for large wavelengths. This may be due to fewer coarse-mode aerosol particles than in previous climatologies for the region (Formenti et al., 2018).

The AAOD spectrum from which we derive AAE is shown in Fig. 7d for both cases. The AAE for the 2016 case is 1.29, while the AAE for the 2017 case is 1.44 . Both AAE values are similar to the results of Bergstrom et al. (2007) and reproduced by Russell et al. (2010) from the SAFARI 
campaign for biomass smoke of 1.45 for wavelengths of 325 to $1000 \mathrm{~nm}$. In situ measurements of AAE from the PSAP showed the average AAE values from the two spirals profiles to be 1.79 for 20 September 2016 and $1.7013 \mathrm{Au}$ gust 2017 for the 470-660 nm wavelength range (Dobracki et al., 2019). Differences between radiatively derived and in situ measured values for both AAE and SSA may be due to differences in aerosol humidification; the irradiances measured by SSFR and the resulting aerosol properties represent the aerosol in ambient conditions (Pistone et al., 2019). The in situ instruments, however, control the relative humidity while the aerosol is measured, potentially causing discrepancies. Biases may also be present in the in situ absorption that propagates to bias in SSA, due to known issues with measuring absorption on a filter (Pistone et al., 2019). When the aerosolintensive properties are derived using our new approach, the aerosol optical properties are radiatively consistent with the measured irradiance and the ambient optical thickness, therefore allowing us to establish a more direct estimate of DARE.

\subsection{DARE and critical albedo}

Figure 8a shows the TOL radiative effect as a percent of the incoming radiation at $501 \mathrm{~nm}$ as a function of the underlying albedo for 20 September 2016 and the northern and southern cases from 13 August 2017. Figure 8b shows example spectra from each case with associated error bars. A positive DARE value indicates that the aerosol warms the layer. For the 20 September 2016 case, the scene albedo, which we consider the average of all the albedo values, is 0.5 at $501 \mathrm{~nm}$, with a corresponding TOL DARE of $9.6 \pm 0.9 \%$ (percentage of incoming irradiance). For the 13 August 2017 North case, the scene albedo of 0.03 results in a TOL DARE of $-0.61 \pm 2.01 \%$, while the scene albedo of 0.27 for $13 \mathrm{Au}$ gust 2017 South results in a TOL DARE of $5.45 \pm 1.92 \%$. As can be seen in Fig. 8, the DARE from the 20 September 2016 case is larger than the 13 August 2016 cases, in large part due to the higher AOD values in the 20 September 2016 case. At the BOL, DARE is always negative since the amount of radiation reaching that altitude decreases when there is an aerosol layer present due to the scattering and absorption that occurs. For this reason, we do not show the BOL DARE results visually. At the scene albedos listed above, the BOL DARE values at $501 \mathrm{~nm}$ are $-7.27 \pm 0.9 \%,-8.36 \pm 2.01 \%$, and $-4.37 \pm 1.92 \%$, for 20 September 2016, 13 August 2017 North, and 13 August 2017 South, respectively. For the 2017 cases, the clouds were broken on the northern section and homogeneous on the southern section. The TOL radiative effect crosses from negative to positive with increasing albedo, illustrating that the same aerosol has a warming effect in the south and a cooling effect in the north due to the differences in the underlying cloud. This is similar to the conclusions of Keil and Haywood (2003), Chand et al. (2009), and Meyer et al. (2013), who also find that DARE decreases as the underlying clouds darken, eventually becoming negative. We find that the critical albedo is 0.21 at $501 \mathrm{~nm}$ for 20 September 2016 and 0.26 for 13 August 2017. Chand et al. (2009), along with Meyer et al. (2013) and many other studies, choose to normalize the radiative effect by the aerosol optical depth, a quantity known as the radiative forcing efficiency (RFE), to isolate the cloud effect from the aerosol loading on DARE. For this region, Chand et al. (2009) find that the transition point from positive to negative RFE is at the critical cloud fraction of 0.4 . Since we are interested in the radiative effects as a function of both the cloud and aerosol properties, we choose not to translate DARE into RFE since it (a) removes the dependence on the aerosol loading and (b) may not linearly scale with mid-visible AOD, with evidence suggesting that the increase depends upon the cloud albedo (Cochrane et al., 2019). We can, however, convert critical albedo into critical cloud fraction and critical optical thickness. For a cloud fraction of $100 \%$ and using the two-stream approximation (Coakley and Chylek, 1975), a critical albedo of $0.21(0.26)$ corresponds to a critical optical thickness of 1.5 (1.35). Assuming the mean cloud albedo value of 0.5 used by Chand et al. (2009) (determined on the basis of July-October $5^{\circ} \times 5^{\circ}$ mean and standard deviation of MODIS-retrieved cloud optical depths), a critical albedo value of $0.21(0.26)$ and a $g$ value of $0.56(0.27)$ would translate into a critical cloud fraction of $0.42(0.52)$. This is consistent with their finding of the critical cloud fraction to be 0.4. Podgorny and Ramanathan (2001), however, find a much lower critical cloud fraction even with a higher SSA. Chand et al. (2009) attribute this discrepancy to differences in cloud albedo, acknowledging that accurate cloud albedo values are crucial in determining aerosol radiative effects. In reality, one cannot simply fix the cloud albedo to a single value; the true albedo, measured from the BOL leg of the radiation wall, at $501 \mathrm{~nm}$ for 20 September 2016 ranges from 0.39 to 0.59 , while the 13 August 2016 albedo ranges from 0.06 to 0.39 . Using critical albedo instead of critical cloud fraction or optical thickness circumvents these problems.

Chand et al. (2009) find that the critical cloud fraction is particularly sensitive to the SSA and is the greatest source of explicitly estimated uncertainty in their study. In our study, the largest uncertainty contributor to the DARE calculation and, similarly, critical albedo, is case dependent, though the SSA represents a significant fraction of the error across all cases for wavelengths of $355-660 \mathrm{~nm}$. This can be seen in Fig. 9, which shows an example of the uncertainty contributions of each input parameter to the DARE calculation for one point from each case. The 20 September 2016 DARE error is dominated by the SSA, while the 13 August 2017 North case is dominated by the $g$ error. The 13 August 2017 South case has nearly equally large contributions from SSA and $g$. It should be noted that the uncertainty partitioning changes for different points along the radiation wall. Quantifying the individual component uncertainties, especially the albedo uncertainty, is an advancement to satellite-based studies that focus on only quantifying the aerosol parameter un- 
(a)

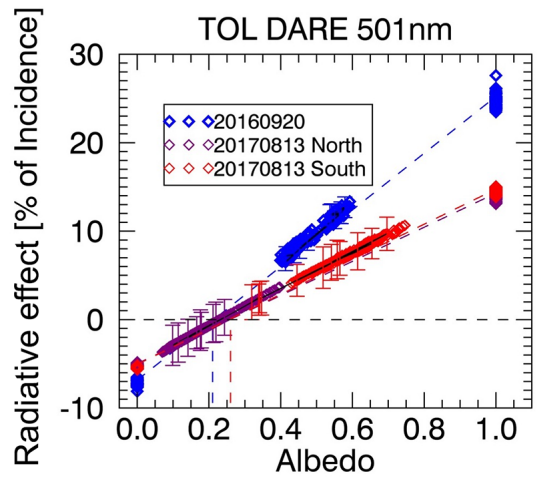

(b)

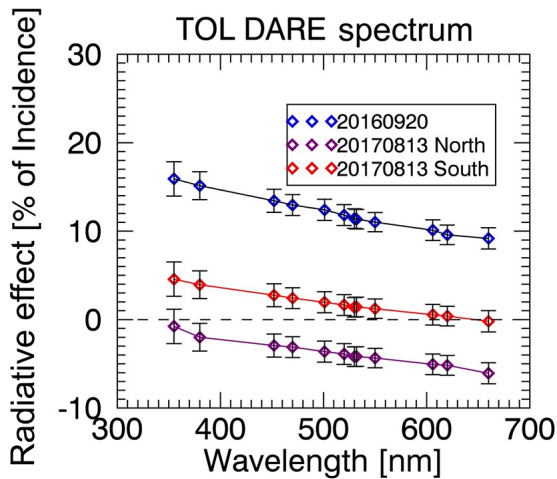

Figure 8. (a) The top of layer DARE at $501 \mathrm{~nm}$ as a function of the underlying albedo. The critical albedo at $501 \mathrm{~nm}$ is 0.2 across all three cases: 20 September 2016 in blue; 13 August 2017 North in purple; 13 August 2017 South in red. The uncertainty estimates are shown for a subset of data points for each case. (b) An example of a DARE spectrum with associated uncertainties for all three cases: 20 September 2016 in blue; 13 August 2017 North in purple; 13 August 2017 South in red. The error bars slightly decrease with increasing wavelength for each case.

(a)

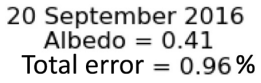
Albedo $=0.41$
Total error $=0.96 \%$

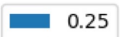

0.20

0.35

0.83

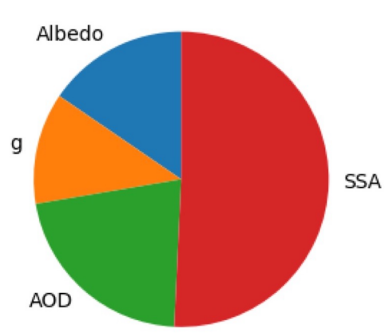

(b)

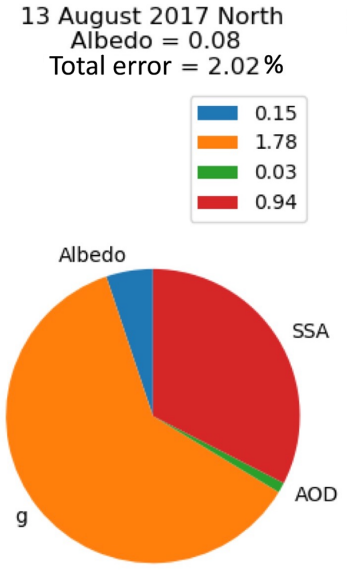

(c) 13 August 2017 South

Albedo $=0.32$

Total error $=1.97 \%$
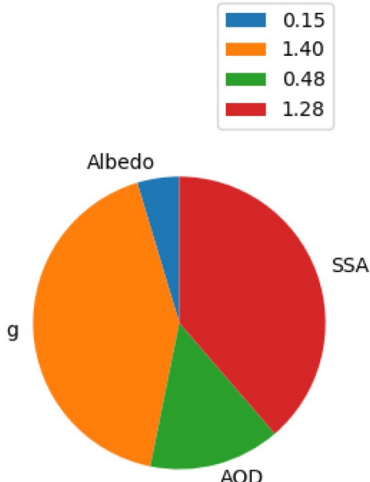

Figure 9. The error contributions of $g$ (orange), AOD (green), albedo (blue), and SSA (red) for one example each from (a) 20 September 2016 , (b) 13 August 2017 North and (c) 13 August 2017 South. Units are the percentage of incident radiation.

certainties. The uncertainty due to the underlying clouds in DARE calculations, while known to be important, is often not emphasized or quantified since the cloud albedo cannot be measured directly from space. Despite the differences between previous studies and our work, the results all highlight the importance for accurate optical properties of both the aerosol and underlying cloud layers, since the radiative effect of an aerosol layer so clearly depends on both.

\section{Summary and future work}

Aircraft observations, such as those taken during ORACLES, help capture some of the information relevant for determining the aerosol radiative effect in the presence of clouds that satellite measurements are unable to obtain: aerosol SSA, $g$, and cloud albedo. The aerosol properties, SZA, and albedo differed between the cases examined in this work, and the critical albedo was 0.21 for 20 September 2016 and 0.26 for 13 August 2017. The critical albedo parameter describes how a certain type of aerosol is affected by the underlying surface despite scene differences. If shown to be applicable across many scenes, this parameter could be very useful for parameterizations of DARE above clouds for biomass burning aerosol.

DARE, by definition, requires radiative transfer modeling, and our calculations utilize AOD from 4STAR, measured cloud albedo from SSFR, and retrieved values of SSA and $g$. Using SSFR irradiance measurements from a square spiral, which is made possible by SSFR in conjunction with ALP, turned out to be crucial for determining aerosol-intensive properties for the inhomogeneous or changing situations encountered during ORACLES. The newly developed retrieval 
algorithm allowed us to separate cloud effects from aerosol effects through filtering methods which account for a changing cloud field by eliminating regions of high variability and points that are subjected to 3-D effects. We determine this through the $H$ parameter, a proxy for 3-D cloud effects, which is near zero for the filtered spiral measurements but not for the "wall" measurements (stacked legs). The spiral method also considerably decreases the uncertainty on the retrieved SSA compared to the radiation wall method, which is of key importance since the SSA is the largest contributor to the overall DARE uncertainty.

As expected, we found that DARE increases with AOD. However, upon examining other cases (Cochrane et al., 2019), evidence suggests that the increase is not linear with AOD and depends upon the cloud albedo. This puts into question the utility of the concept of radiative forcing efficiency that has been widely used in studies such as Pilewskie et al. (2003), Bergstrom et al. (2003), Redemann et al. (2006), Chand et al. (2009), Schmidt et al. (2010a), and LeBlanc et al. (2012). Although these references did not explicitly assume linearity, one must be cautious when using RFE to make the link from satellite-derived optical thickness to DARE. This provides motivation for developing a new approach for establishing such a link, for which the critical albedo could provide that connection as it accounts for both the aerosol and cloud properties.
Future work will also be aimed at verifying whether the DARE-albedo relationship found in this case study is generally valid across scenes with different cloud spatial inhomogeneities, different sun angles, etc. Work will also be aimed at assessing the remaining suitable ORACLES cases by applying the methodologies presented in this paper to determine regional values of SSA, $g$, DARE, and heating rate profiles. The results will be used to parameterize the radiative effects in terms of appropriate quantities such as the AAOD and will be presented in a follow-up paper (Cochrane et al., 2019). It is also important that the SSA be checked for consistency with SSA retrieved from other instruments from the ORACLES campaign, such as in Pistone et al. (2019).

Data availability. The P3 and ER2 observational data are available at: https://doi.org/10.5067/Suborbital/ORACLES/P3/2016_V1 (ORACLES Science Team, 2017b) for the 2016 P3 data, https://doi.org/10.5067/Suborbital/ORACLES/ER2/2016_V1 (ORACLES Science Team, 2017a) for the 2016 ER2 data, and https://doi.org/10.5067/Suborbital/ORACLES/P3/2017_V1 (ORACLES Science Team, 2019) for the 2017 P3 data. 


\section{Appendix A: Uncertainty estimates}

This Appendix describes the full methodology used to obtain the uncertainties presented in the main body of this work. Some equations are repeated from the main body in an effort to make the derivation comprehensible.

The uncertainty analysis provides a way for us to evaluate our absorptance derivation methods and SSA retrieval and to assess whether our DARE calculations are more successful than existing methods. Though we do not use radiation wall irradiance pairs to determine aerosol-intensive properties due to the inability to separate $V$ from $H$, we perform the uncertainty analysis for illustration only where we must inaccurately assume $H=0$. We derive the uncertainty for both the radiation wall and spiral methods of finding absorption and propagate those errors into the error of SSA. We assume measurements with independent and random uncertainties and therefore propagate errors by adding in quadrature.

\section{A1 Absorptance}

The uncertainty on absorptance is calculated from two separate methods: the irradiance pair method, completed using measurements from the radiation wall, and the spiral method which uses data taken only during the aircraft spiral.

The irradiance pairs method relies on determining the vertical flux divergence $\left(V_{\lambda}\right)$ from two collocated irradiance measurement pairs above and below the aerosol layer $\left(F_{\lambda}^{\downarrow}\right.$, top , $F_{\lambda, \text { top }}^{\uparrow}$, and $F_{\lambda \text {, bot }}^{\downarrow}, F_{\lambda \text {, bot }}^{\uparrow}$ ) following

$$
\begin{aligned}
V_{\lambda} & =\frac{\left(F_{\lambda, \text { top }}^{\text {net }}-F_{\lambda, \text { bot }}^{\text {net }}\right)}{F_{\lambda, \text { top }}^{\downarrow}} \\
& =\frac{\left(F_{\lambda, \text { top }}^{\downarrow}-F_{\lambda, \text { top }}^{\uparrow}\right)-\left(F_{\lambda, \text { bot }}^{\downarrow}-F_{\lambda, \text { bot }}^{\uparrow}\right)}{F_{\lambda, \text { top }}^{\downarrow}} .
\end{aligned}
$$

The absorptance would in theory (Song et al., 2016) be found by subtracting the horizontal photon transport from $V_{\lambda}$ :

$A_{\lambda}=V_{\lambda}-H_{\lambda}$.

We assume that $H_{\lambda}=0$ for the purposes of deriving a nominal uncertainty value, though this is an inappropriate assumption for the conditions encountered during ORACLES. We have no way of correcting for $H_{\lambda}$, and therefore the following calculations represent the nominal case where cloud variability has no effect. With this assumption, the absorptance becomes

$$
A_{\lambda}=\frac{\left(F_{\lambda, \text { top }}^{\downarrow}-F_{\lambda, \text { top }}^{\uparrow}\right)-\left(F_{\lambda, \text { bot }}^{\downarrow}-F_{\lambda, \text { bot }}^{\uparrow}\right)}{F_{\lambda, \text { top }}^{\downarrow}},
$$

and the uncertainty is calculated as

$$
\begin{aligned}
& \delta A_{\lambda}=\sqrt{\left(\frac{-1}{F_{\lambda, \text { top }}^{\downarrow}} \delta F_{\lambda, \text { top }}^{\uparrow}\right)^{2}+\left(\frac{-1}{F_{\lambda, \text { top }}^{\downarrow}} \delta F_{\lambda, \text { bot }}^{\downarrow}\right)^{2}} \\
& \overline{+\left(\frac{-1}{F_{\lambda, \text { top }}^{\downarrow}} \delta F_{\lambda, \text { bot }}^{\uparrow}\right)^{2}+\left(\frac{-1}{F_{\lambda, \text { top }}^{\downarrow}} \delta F_{\lambda, \text { top }}^{\downarrow}\right)^{2},}
\end{aligned}
$$

where $\delta F$ is the upper limit of the SSFR radiometric uncertainty, $5 \%$. The uncertainty depends on the magnitude of the downwelling irradiance, which is demonstrated clearly in Fig. A1. At the shorter wavelengths where the incoming spectrum is the largest, the uncertainties are much larger than for the longer wavelengths.

The spiral method is based on many measurements taken throughout the profile of the atmospheric column. We therefore rely on linearly fitting weighted AOD and irradiance measurements to determine the top of aerosol layer and bottom of aerosol layer net irradiances.

The following linear fits determine the irradiance values (upwelling/downwelling) at the top $\left(\mathrm{AOD}_{532}=\right.$ minimum) and bottom of the aerosol layer $\left(\mathrm{AOD}_{532}=\right.$ maximum $)$ :

$F_{\lambda}^{\uparrow}=a_{\lambda}^{\uparrow}+b_{\lambda}^{\uparrow} \times \mathrm{AOD}_{532}$,

$F_{\lambda}^{\downarrow}=a_{\lambda}^{\downarrow}+b_{\lambda}^{\downarrow} \times \mathrm{AOD}_{532}$,

where $a_{\lambda}$ and $b_{\lambda}$ are the slope and intercept of the linear fit lines.

The uncertainties on the weighted fit parameters $a_{\lambda}, b_{\lambda}$ are calculated according to

$$
\begin{aligned}
\sigma_{a} & =\frac{\sum w \times\left(\mathrm{AOD}_{532}\right)^{2}}{\Delta}, \\
\sigma_{b} & =\frac{\sum w}{\Delta}, \\
w & =\frac{1}{\sigma_{i}^{2}},
\end{aligned}
$$

where $\Delta=\sum w \times \sum w \times\left(\mathrm{AOD}_{532}\right)^{2}-\left(\sum w \times \mathrm{AOD}_{532}\right)^{2}$ and $\sigma_{i}$ represent the measurement error. Therefore, when substituting these into Eq. (3), the absorptance can be found by

$$
A_{\lambda}=\frac{\mathrm{AOD}_{532}^{\max } \times\left(b_{\lambda}^{\uparrow}-b_{\lambda}^{\downarrow}\right)}{a_{\lambda}^{\downarrow}},
$$

and the uncertainty on the absorptance is

$$
\begin{aligned}
& \delta A_{\lambda}=\sqrt{\left(\frac{\mathrm{d} A_{\lambda}}{\mathrm{dAOD}_{532}^{\max }} \times \delta \mathrm{AOD}_{532}^{\max }\right)^{2}+\left(\frac{\mathrm{d} A_{\lambda}}{\mathrm{d} a_{\lambda}^{\downarrow}} \times \sigma_{a, \lambda}^{\downarrow}\right)^{2}} \\
& \overline{+\left(\frac{\mathrm{d} A_{\lambda}}{\mathrm{d} b_{\lambda}^{\uparrow}} \times \sigma_{b, \lambda}^{\uparrow}\right)^{2}+\left(\frac{\mathrm{d} A_{\lambda}}{\mathrm{d} b_{\lambda}^{\downarrow}} \times \sigma_{b, \lambda}^{\downarrow}\right)^{2}},
\end{aligned}
$$




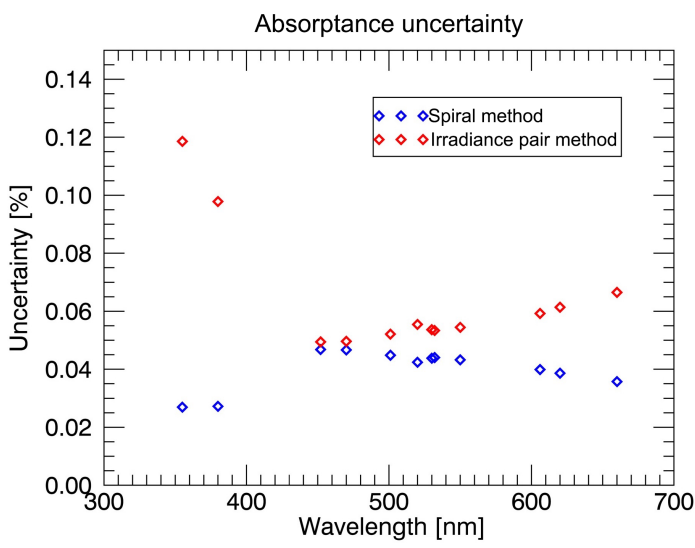

Figure A1. The uncertainty values for the absorptance derivation from the spiral method, shown in blue, and the irradiance pairs method, shown in red, for 20 September 2016. The figure is similar for 13 August 2017. The uncertainty is significantly reduced with the spiral method, especially at the shortest wavelengths where the incoming irradiance is largest. The uncertainty estimate for the irradiance pairs method depends upon the value of the incoming irradiance, which is largest at the shortest wavelengths.

where $\sigma_{a, b}^{\downarrow, \uparrow}$ are the uncertainties on the linear fit parameters. The spiral method compared to the radiation wall method reduces the absorptance uncertainty from 0.05 to 0.02 at $501 \mathrm{~nm}$ for 20 September 2016, which is visualized in Fig. A1, and from 0.07 to 0.05 at $501 \mathrm{~nm}$ for 13 August 2017.

\section{A2 SSA}

The SSA retrieval from the spiral measurements produces the uncertainty, while the SSA calculation for the wall illustration does not. In order to estimate the uncertainty, we must propagate the absorptance error into the SSA.

To simplify propagation of errors, we determine the relationship between absorptance and AAOD by an exponential fit determined through 1-D radiative transfer calculations:

$A_{\lambda}=c_{1}\left(1-e^{-c_{2} \times \frac{\mathrm{AAOD}_{\lambda}}{\mu}}\right)$,

where $\mu=\cos (s z a)$.

The constants $c_{1}$ and $c_{2}$ are presented in Appendix Tables 1a and 2a, and an example of the exponential fit at $380 \mathrm{~nm}$ between absorptance and AAOD is shown in Appendix Fig. A2.

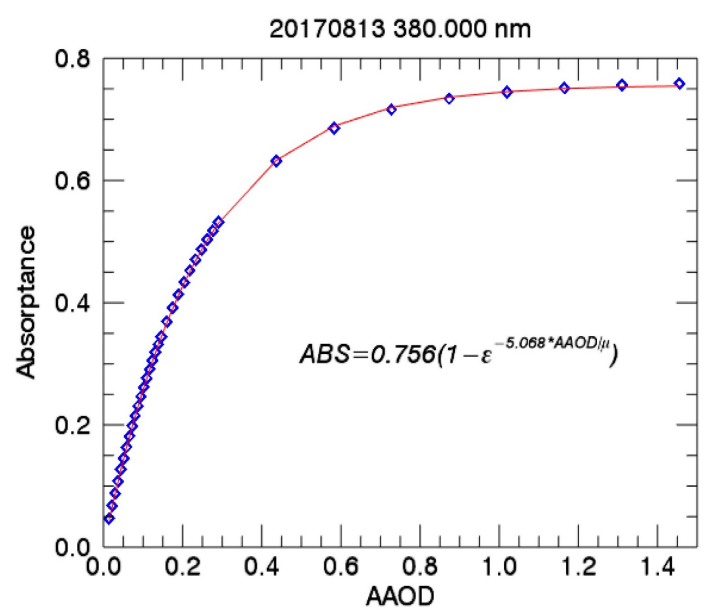

Figure A2. Radiative transfer calculations at $380 \mathrm{~nm}$ of the relationship between absorptance and AAOD. The constant values $c_{1}$ and $c_{2}$ for this case at this wavelength are 0.756 and -5.086 , respectively.

Table A1. Constant values $c_{1}$ and $c_{2}$ determined by radiative transfer calculations for Eq. (A15) for 20 September 2016.

\begin{tabular}{lrr}
\hline Wavelength (nm) & $\mathrm{C} 1$ & $\mathrm{C} 2$ \\
\hline 355 & 0.797 & -2.811 \\
380 & 0.794 & -2.836 \\
452 & 0.794 & -2.794 \\
470 & 0.797 & -2.773 \\
501 & 0.798 & -2.763 \\
520 & 0.797 & -2.77 \\
530 & 0.797 & -2.767 \\
532 & 0.796 & -2.773 \\
550 & 0.80 & -2.75 \\
606 & 0.805 & -2.711 \\
620 & 0.803 & -2.727 \\
660 & 0.812 & -2.666 \\
\hline
\end{tabular}

The AAE and AAOD are determined as follows:

$$
\begin{aligned}
& \mathrm{AAOD}=(1-\mathrm{SSA}) \times \mathrm{AOD}, \\
& \mathrm{AAOD}=\left(\mathrm{AAOD}_{500} \times \frac{\lambda}{\lambda_{500}}\right)^{-\mathrm{AAE}} .
\end{aligned}
$$

Equation (A12a) can be combined with Eqs. (A13a) and (A13b) and solved for SSA:

$\operatorname{SSA}_{\lambda}=1+\frac{\mu \times \ln \left(1-\frac{A_{\lambda}}{c_{1}}\right)}{\operatorname{AOD}_{\lambda} \times c_{2}}$

Equation (A14) provides us with a relationship for which we can calculate the uncertainty on SSA. 
Table A2. Constant values $c_{1}$ and $c_{2}$ determined by radiative transfer calculations for Eq. (A15) for 13 August 2017.

\begin{tabular}{lrr}
\hline Wavelength $(\mathrm{nm})$ & $\mathrm{C} 1$ & $\mathrm{C} 2$ \\
\hline 355 & 0.761 & 5.147 \\
380 & 0.756 & 5.068 \\
452 & 0.777 & 4.812 \\
470 & 0.785 & 4.759 \\
501 & 0.788 & 4.739 \\
520 & 0.793 & 4.710 \\
530 & 0.794 & 4.709 \\
532 & 0.793 & 4.705 \\
550 & 0.801 & 4.636 \\
606 & 0.819 & 4.465 \\
620 & 0.819 & 4.479 \\
660 & 0.835 & 4.321 \\
\hline
\end{tabular}

The radiation wall SSA uncertainty is therefore calculated according to

$\delta \mathrm{SSA}_{\lambda}=\sqrt{\left(\frac{\mathrm{dSSA}_{\lambda}}{\mathrm{dAOD}_{\lambda}} \times \delta \mathrm{AOD}_{\lambda}\right)^{2}+\left(\frac{\mathrm{dSSA}_{\lambda}}{\mathrm{d} A_{\lambda}} \times \delta A_{\lambda}\right)^{2}}$,

where $\quad \frac{\mathrm{dSSA}_{\lambda}}{\mathrm{dAOD}}=\left(\frac{-1}{\mathrm{AOD}_{\lambda}^{2}}\right) \times \frac{\mu \times \ln \left(1-\frac{A_{\lambda}}{c_{1, \lambda}}\right)}{c_{2, \lambda}} \quad$ and $\quad \frac{\mathrm{dSSA}}{\mathrm{d} A_{\lambda}}=$ $\left(\frac{\mu}{\operatorname{AOD}_{\lambda} \times c_{2, \lambda}}\right) \times\left(\frac{1}{A_{\lambda}-c_{1, \lambda}}\right)$.

Figure $7 \mathrm{a}$ and $\mathrm{b}$ clearly show that the spiral method significantly decreases the SSA uncertainty estimates compared to the irradiance pairs method. The uncertainty from the irradiance pairs method would be even larger if we considered the uncertainty due to non-zero $H$. 
Author contributions. SC collected SSFR data, performed the bulk of the analysis, and wrote the majority of the paper with input from the other authors. KS collected SSFR data, helped with the methodology development and data analysis, and helped with developing, writing, and editing the paper. HC, PP, and SK helped with the data collection of SSFR. JR was one of the PIs for the ORACLES campaign and provided 4STAR data. SL was the PI of the 4STAR instrument and helped with the retrieval methodology. KP, MK, MR, YS, and $C F$ provided 4 STAR data. SP and KM provided eMAS data. RF, $\mathrm{SB}$, and $\mathrm{CH}$ provided HSRL data. $\mathrm{SH}, \mathrm{SF}$, and AD provided in situ data. SD was on the leadership team for the ORACLES project and helped advise data use. All the co-authors helped in the reviewing and editing of the paper.

Competing interests. The authors declare that they have no conflict of interest.

Special issue statement. This article is part of the special issue "New observations and related modelling studies of the aerosolcloud-climate system in the Southeast Atlantic and southern Africa regions (ACP/AMT inter-journal SI)". It is not associated with a conference.

Acknowledgements. This work was supported by NASA grant NNX15AF62G. We thank the ORACLES deployment support teams and the science team for a successful and productive mission. We thank Warren Gore of NASA AMES for his support during the ORACLES mission. Thank you to each of the instrument teams who provided data and expertise on using them. Thank you to Matthew Norgren of CU Boulder, who was helpful during the initial draft-writing process.

Financial support. This research has been supported by NASA (grant no. NNX15AF62G).

Review statement. This paper was edited by Jérôme Riedi and reviewed by two anonymous referees.

\section{References}

Bergstrom, R. W., Pilewskie, P., Russell, P. B., Redemann, J., Bond, T. C., Quinn, P. K., and Sierau, B.: Spectral absorption properties of atmospheric aerosols, Atmos. Chem. Phys., 7, 5937-5943, https://doi.org/10.5194/acp-7-5937-2007, 2007.

Bergstrom, R. W., Schmidt, K. S., Coddington, O., Pilewskie, P., Guan, H., Livingston, J. M., Redemann, J., and Russell, P. B.: Aerosol spectral absorption in the Mexico City area: results from airborne measurements during MILAGRO/INTEX B, Atmos. Chem. Phys., 10, 6333-6343, https://doi.org/10.5194/acp10-6333-2010, 2010.

Bucholtz, A., Bluth, R. T., Kelly, B., Taylor, S., Batson, K., Sarto, A. W., Tooman, T. P., and McCoy Jr., R. F.: The Stabilized Ra- diometer Platform (STRAP) - An Actively Stabilized Horizontally Level Platform for Improved Aircraft Irradiance Measurements, J. Atmos. Ocean. Tech., 25, 2161-2175, 2008.

Burton, S. P., Hostetler, C. A., Cook, A. L., Hair, J. W., Seaman, S. T., Scola, S., Harper, D. B., Smith, J. A., Fenn, M. A., Ferrare, R. A., Saide, P. E., Chemyakin, E. V., and Müller, D.: Calibration of a high spectral resolution lidar using a Michelson interferometer, with data examples from ORACLES, Appl. Optics, 57, 60616075, https://doi.org/10.1364/AO.57.006061, 2018.

Coakley, J. A. and P. Chylek,: The two-stream approximation in radiative transfer: Including the angle of the incident radiation, J. Atmos. Sci., 32, 409-418, https://doi.org/10.1175/15200469(1975)032<0409:TTSAIR>2.0.CO;2, 1975.

Cochrane, S., Schmidt, K. S., Chen, H., Pilewskie, P., Kittelman, S., Gore, W., Redemann, J., LeBlanc, S., Pistone, K., Ferrare, R., Burton, S., Hostetler, C., Howell, S., and Dobracki, A.: The Dependence of Aerosol Radiative Effects on Spectral Aerosol Properties Derived from Aircraft Measurements: Results from the ORACLES 2016 and ORACLES 2017 Experiments, in preparation, 2019.

Chen, H., Cochrane, S., LeBlanc, S., Schmidt, K. S., Redemann, J., Pistone, K., and Kacenelenbogen, M.: Direct Aerosol Radiative Effects based on Aircraft Measurements during ORACLES 2016-2018, in preparation, 2019.

Chand, D., Wood, R., Anderson, T. L., Satheesh, S. K., and Charlson, R. J.: Satellite-derived direct radiative effect of aerosols dependent on cloud cover, Nat. Geosci., 2, 181-184, 2009.

Coddington, O. M., Pilewskie, P., Redemann, J., Platnick, S., Russell, P. B., Schmidt, K. S., and Vukicevic, T.: Examining the impact of overlying aerosols on the retrieval of cloud optical properties from passive remote sensing, J. Geophys. Res.-Atmos., 115, D10211, https://doi.org/10.1029/2009JD012829, 2010.

de Graaf, M., Tilstra, L. G., Wang, P., and Stammes, P.: Retrieval of the aerosol direct radiative effect over clouds from spaceborne spectrometry, J. Geophys. Res.-Atmos., 117, D07207, https://doi.org/10.1029/2011JD017160, 2012.

de Graaf, M., Schulte, R., Peers, F., Waquet, F., Tilstra, L. G., and Stammes, P.: Comparison of south Atlantic aerosol direct radiative effect overclouds from SCIAMACHY, POLDER and OMI/MODIS, Atmos. Chem. Phys. Discuss., https://doi.org/10.5194/acp-2019-545, in review, 2019.

Dobracki, A., Freitag, S., Howell, S., Podolske, J., Redemann, J., Saide, P., Sedlacek, A., and Zuidema, P.: Total Organic Carbon Loss and Changes in Bulk Chemical Composition Seen in Vertically Stratified Aged African Biomass Burning Plumes over the Southeast Atlantic Oceam during ORACLES, in: American Meteorological Society 99th Annual Meeting/11th Symposium on Aerosol-Cloud-Climate Interactions, Phoenix, USA, 6-10 January 2019, 2.2, 2019.

Dubovik, O. and King, M. D.: A flexible inversion algorithm for retrieval of aerosol optical properties from Sun and sky radiance measurements, J. Geophys. Res., 105, 20673-20696, 2000.

Dunagan, S., Johnson, R., Zavaleta, J., Russell, P., Schmid, B., Flynn, C., Redemann, J., Shinozuka, Y., Livingston, J., and Segal Rozenhaimer, M.: Spectrometer for Sky-Scanning Sun-Tracking Atmospheric Research (4STAR): Instrument Technology, Remote Sensing, 5, 3872-3895, https://doi.org/10.3390/rs5083872, 2013. 
Eck, T. F., Holben, B., Ward, D., Mukelabai, M., Dubovik, O., Smirnov, A., Schafer, J., Hsu, N., Piketh, S., Queface, A., Roux, J., Swap, R., and Slutsker, I.: Variability of biomass burning aerosol optical characteristics in southern Africa during the SAFARI 2000 dry season campaign and a comparison of single scattering albedo estimates from radiometric measurements, J. Geophys. Res.-Atmos., 108, 8477, https://doi.org/10.1029/2002JD002321, 2003a.

Eck, T. F., Holben, B. N., Reid, J. S., O’Neill, N. T., Schafer, J. S., Dubovik, O., Smirnov, A., Yamasoe, M. A., and Artaxo, P.: High aerosol optical depth biomass burning events: A comparison of optical properties for different source regions, Geophys. Res. Lett., 30, 2035, https://doi.org/10.1029/2003GL017861, 2003b.

Ehrlich, A., Bierwirth, E., Istomina, L., and Wendisch, M.: Combined retrieval of Arctic liquid water cloud and surface snow properties using airborne spectral solar remote sensing, Atmos. Meas. Tech., 10, 3215-3230, https://doi.org/10.5194/amt10-3215-2017, 2017.

Ellis, T. A., Myers, J., Grant, P., Platnick, S., Guerin, D. C., Fisher, J., Song, K., Kimchi, J., Kilmer, L., LaPorte, D. D., and Moeller, C. C.: The NASA enhanced MODIS airborne simulator, Proc. SPIE 8153, Earth Observing Systems XVI, 81530N (13 September 2011), https://doi.org/10.1117/12.894482, 2011.

Emde, C., Buras-Schnell, R., Kylling, A., Mayer, B., Gasteiger, J., Hamann, U., Kylling, J., Richter, B., Pause, C., Dowling, T., and Bugliaro, L.: The libRadtran software package for radiative transfer calculations (version 2.0.1), Geosci. Model Dev., 9, 1647-1672, https://doi.org/10.5194/gmd-9-1647-2016, 2016.

Formenti, P., Piketh, S. J., Namwoonde, A., Klopper, D., Burger, R., Cazaunau, M., Feron, A., Gaimoz, C., Broccardo, S., Walton, N., Desboeufs, K., Siour, G., Hanghome, M., Mafwila, S., Omoregie, E., Junkermann, W., and Maenhaut, W.: Three years of measurements of light-absorbing aerosols over coastal Namibia: seasonality, origin, and transport, Atmos. Chem. Phys., 18, 17003-17016, https://doi.org/10.5194/acp-18-17003-2018, 2018.

Fraser, R. S. and Kaufman, Y. J.: The relative importance of aerosol scattering and absorption in remote sensing, IEEE J. Geosci. Remote, GE-23, 525-633, 1985.

Giles, D. M., Holben, B. N., Eck, T. F., Sinyuk, A., Smirnov, A., Slutsker, I., Dickerson, R. R., Thompson, A. M., and Schafer, J. S.: An analysis of AERONET aerosol absorption properties and classifications representative of aerosol source regions, J. Geophys. Res., 117, D17203, https://doi.org/10.1029/2012JD018127, 2012.

Hair, J. W., Hostetler, C. A., Cook, A. L., Harper, D. B., Ferrare, R. A., Mack, T. L., Welch, W., Isquierdo, L. R., and Hovis, F. E.: Airborne high spectral resolution lidar for profiling aerosol optical properties, Appl. Optics, 47, 6734-6752, 2008.

Haywood, J. M., Osborne, S. R., and Abel, S. J.: The effect of overlying absorbing aerosol layers on remote sensing retrievals of cloud effective radius and cloud optical depth, Q. J. Roy. Meteor. Soc., 130, 779-800, 2004.

Jethva, H., Torres, O., Remer, L. A., and Bhartia, P. K.: A color ratio method for simultaneous retrieval of aerosol and cloud optical thickness of above-cloud absorbing aerosols from passive sensors: Application to MODIS measurements, IEEE T. Geosci. Remote, 51, 3862-3870, 2013.
Jethva, H., Torres, O., Waquet, F., Chand, D., and Hu, Y.: How do A-train sensors intercompare in the retrieval of above, cloud aerosol optical depth, A case study-based assessment, Geophys. Res. Lett., 41, 186-192, https://doi.org/10.1002/(ISSN)19448007, 2014.

Kacenelenbogen, M., Vaughan, M. A., Redemann, J., Hoff, R. M., Rogers, R. R., Ferrare, R. A., Russell, P. B., Hostetler, C. A., Hair, J. W., and Holben, B. N.: An accuracy assessment of the CALIOP/CALIPSO version 2/version 3 daytime aerosol extinction product based on a detailed multi-sensor, multi-platform case study, Atmos. Chem. Phys., 11, 3981-4000, https://doi.org/10.5194/acp-11-3981-2011, 2011.

Kacenelenbogen, M. S., Vaughan, M. A., Redemann, J., Young, S. A., Liu, Z., Hu, Y., Omar, A. H., LeBlanc, S., Shinozuka, Y., Livingston, J., Zhang, Q., and Powell, K. A.: Estimations of global shortwave direct aerosol radiative effects above opaque water clouds using a combination of A-Train satellite sensors, Atmos. Chem. Phys., 19, 4933-4962, https://doi.org/10.5194/acp19-4933-2019, 2019.

Keil, A. and Haywood, J. M.: Solar radiative forcing by biomass burning aerosol particles during SAFARI 2000: A case study based on measured aerosol and cloud properties, J. Geophys. Res., 108, 8467, https://doi.org/10.1029/2002JD002315, 2003.

Kim, M.-H., Omar, A. H., Tackett, J. L., Vaughan, M. A., Winker, D. M., Trepte, C. R., Hu, Y., Liu, Z., Poole, L. R., Pitts, M. C., Kar, J., and Magill, B. E.: The CALIPSO version 4 automated aerosol classification and lidar ratio selection algorithm, Atmos. Meas. Tech., 11, 6107-6135, https://doi.org/10.5194/amt11-6107-2018, 2018.

Kindel, B. C.: Cloud shortwave spectral radiative properties: Airborne hyperspectral measurements and modeling of irradiance, $\mathrm{PhD}$ thesis, University of Colorado, 2010.

King, M. D., Menzel, W. P., Grant, P. S., Myers, J. S., Arnold, G. T., Platnick, S. E., Gumley, L. E., Tsay, S. C., Moeller, C. C., Fitzgerald, M., Brown, K. S., and Osterwisch, F. G.: Airborne scanning spectrometer for remote sensing of cloud, aerosol, water vapor and surface properties, J. Atmos. Ocean. Tech., 13, 777-794, 1996.

Korras-Carraca, M. B., Pappas, V., Hatzianastassiou, N., and Matsoukas, C.: Global vertically resolved aerosol direct radiation effect from three years of CALIOP data using the FORTH radiation transfer model, Atmos. Res., 224, 138-156, 2019.

Kurucz, R. L.: Synthetic infrared spectra, in Infrared Solar Physics: Proceedings of the 154th Symposium of the International Astronomical Union, edited by: Rabin, D. M., Jefferies, J. T., and Lindsey, C., pp. 523531, Kluwer Acad., Dordrecht, Netherlands, 1992.

LeBlanc, S. E., Schmidt, K. S., Pilewskie, P., Redemann, J., Hostetler, C., Ferrare, R., Hair, J., Langridge, J. M., and Lack, D. A.: Spectral aerosol direct radiative forcing from airborne radiative measurements during CalNex and ARCTAS, J. Geophys. Res., 117, D00V20, https://doi.org/10.1029/2012JD018106, 2012.

LeBlanc, S. E., Redemann, J., Flynn, C., Pistone, K., Kacenelenbogen, M., Segal-Rosenheimer, M., Shinozuka, Y., Dunagan, S., Dahlgren, R. P., Meyer, K., Podolske, J., Howell, S. G., Freitag, S., Small-Griswold, J., Holben, B., Diamond, M., Formenti, P., Piketh, S., Maggs-Kölling, G., Gerber, M., and Namwoonde, A.: Above Cloud Aerosol Optical Depth from airborne observa- 
tions in the South-East Atlantic, Atmos. Chem. Phys. Discuss., https://doi.org/10.5194/acp-2019-43, in review, 2019.

Meyer, K., Platnick, S., Oreopoulos, L., and Lee, D.: Estimating the direct radiative effect of absorbing aerosols overlying marine boundary layer clouds in the southeast Atlantic using MODIS and CALIOP, J. Geophys. Res.-Atmos., 118, 48014815, https://doi.org/10.1002/jgrd.50449, 2013.

Meyer, K., Platnick, S., and Zhang, Z.: Simultaneously inferring above-cloud absorbing aerosol optical thickness and underlying liquid phase cloud optical and microphysical properties using MODIS, J. Geophys. Res.-Atmos., 120, 5524-5547, https://doi.org/10.1002/2015JD023128, 2015.

Myhre, G., Shindell, D., Bréon, F. M., Collins, W., Fuglestvedt, J., Huang, J., Koch, D., Lamarque, J. F., Lee, D., Mendoza, B., Nakajima, T., Robock, A., Stephens, G., Takemura T., and Zhang, H.: Anthropogenic and Natural Radiative Forcing, in: Climate Change 2013: The Physical Science Basis. Contribution of Working Group I to the Fifth Assessment Report of the Intergovernmental Panel on Climate Change, edited by: Stocker, T. F., Qin, D., Plattner, G.-K., Tignor, M., Allen, S. K., Boschung, J., Nauels, A., Xia, Y., Bex, V., and Midgley, P. M., Cambridge University Press, Cambridge, United Kingdom and New York, NY, USA, 2013.

Oikawa, E., Nakajima, T., and Winker, D.: An evaluation of the shortwave direct aerosol radiative forcing using CALIOP and MODIS observations, J. Geophys. Res.-Atmos., 123, 12111233, 2018.

ORACLES Science Team: NASA Ames Earth Science Project Office: Suite of Aerosol, Cloud, and Related Data Acquired Aboard ER2 During ORACLES 2016, Version 1, https://doi.org/10.5067/Suborbital/ORACLES/ER2/2016_V1, 2017a.

ORACLES Science Team: NASA Ames Earth Science Project Office: Suite of Aerosol, Cloud, and Related Data Acquired Aboard P3 During ORACLES 2016, Version 1, https://doi.org/10.5067/Suborbital/ORACLES/P3/2016_V1, 2017b.

ORACLES Science Team: NASA Ames Earth Science Project Office: Suite of Aerosol, Cloud, and Related Data Acquired Aboard P3 During ORACLES 2017, Version 1, https://doi.org/10.5067/Suborbital/ORACLES/P3/2017_V1, 2019

Peers, F., Waquet, F., Cornet, C., Dubuisson, P., Ducos, F., Goloub, P., Szczap, F., Tanré, D., and Thieuleux, F.: Absorption of aerosols above clouds from POLDER/PARASOL measurements and estimation of their direct radiative effect, Atmos. Chem. Phys., 15, 4179-4196, https://doi.org/10.5194/acp15-4179-2015, 2015.

Pilewskie, P., Pommier, J., Bergstrom, R., Gore, W., Howard, S., Rabbette, M., Schmid, B., Hobbs, P. V., and Tsay, S. C.: Solar spectral radiative forcing during the Southern African Regional Science Initiative, J. Geophys. Res., 108, 8486, https://doi.org/10.1029/2002JD002411, 2003.

Pistone, K., Redemann, J., Doherty, S., Zuidema, P., Burton, S., Cairns, B., Cochrane, S., Ferrare, R., Flynn, C., Freitag, S., Howell, S. G., Kacenelenbogen, M., LeBlanc, S., Liu, X., Schmidt, K. S., Sedlacek III, A. J., Segal-Rozenhaimer, M., Shinozuka, Y., Stamnes, S., van Diedenhoven, B., Van Harten, G., and $\mathrm{Xu}, \mathrm{F}$.: Intercomparison of biomass burning aerosol optical properties from in situ and remote-sensing instruments in ORACLES-2016, Atmos. Chem. Phys., 19, 9181-9208, https://doi.org/10.5194/acp-19-9181-2019, 2019.

Podgorny, I. A. and Ramanathan, V.: A modeling study of the direct effect of aerosols over the tropical Indian Ocean, J. Geophys. Res., 106, 24097-24105, 2001.

Redemann, J., Pilewskie, P., Russell, P. B., Livingston, J. M., Howard, S., Schmid, B., Pommier, J., Gore, W., Eilers, J., and Wendisch, M.: Airborne measurements of spectral direct aerosol radiative forcing in the Intercontinental chemical Transport Experiment/Intercontinental Transport and Chemical Transformation of anthropogenic pollution, 2004, J. Geophys. Res., 111, D14210, https://doi.org/10.1029/2005JD006812, 2006.

Ricchiazzi, P., Yang, S., Gautier, C., and Sowle, D.: SBDART: A Research and Teaching Software Tool for PlaneParallel Radiative Transfer in the Earth's Atmosphere, B. Am. Meteor.ol Soc., 79, 2101-2114, https://doi.org/10.1175/15200477(1998)079<2101:SARATS>2.0.CO;2, 1998.

Russell, P. B., Redemann, J., Schmid, B., Bergstrom, R. W., Livingston, J. M., Mcintosh, D. M., Ramirez, S. A., Hartley, S., Hobbs, P. V., Quinn, P. K., Carrico, C. M., Rood, M. J., Ostrom, E., Noone, K. J., Von Hoyningen-Huene, W., and Remer, L.: Comparison of Aerosol Single Scattering Albedos Derived by Diverse Techniques in Two North Atlantic Experiments, J. Atmos. Sci., 59.3, 609-19, 2002.

Russell, P. B., Bergstrom, R. W., Shinozuka, Y., Clarke, A. D., DeCarlo, P. F., Jimenez, J. L., Livingston, J. M., Redemann, J., Dubovik, O., and Strawa, A.: Absorption Angstrom Exponent in AERONET and related data as an indicator of aerosol composition, Atmos. Chem. Phys., 10, 1155-1169, https://doi.org/10.5194/acp-10-1155-2010, 2010.

Sayer, A. M., Hsu, N. C., Bettenhausen, C., Lee, J., Redemann, J., Schmid, B., and Shinozuka, Y.: Extending "Deep Blue" aerosol retrieval coverage to cases of absorbing aerosols above clouds: Sensitivity analysis and first case studies, J. Geophys. Res.-Atmos., 121, 4830-4854, https://doi.org/10.1002/2015JD024729, 2016.

Schmid, B. and Wehrli, C.: Comparison of Sun photometer calibration by use of the Langley technique and the standard lamp, Applied Opt., 34, 4500-4512, 1995.

Schmid, J.: The SEVIRI Instrument Proceedings of the 2000 EUMETSAT Meteorological Satellite. Data User's Conference, Bologna, Italy, 29 May-2 June 2000, Darmstadt, Germany, EUMETSAT ed (2000), 13-32, 2000.

Schmidt, K. S., Pilewskie, P., Bergstrom, R., Coddington, O., Redemann, J., Livingston, J., Russell, P., Bierwirth, E., Wendisch, M., Gore, W., Dubey, M. K., and Mazzoleni, C.: A new method for deriving aerosol solar radiative forcing and its first application within MILAGRO/INTEX-B, Atmos. Chem. Phys., 10, 78297843, https://doi.org/10.5194/acp-10-7829-2010, 2010a.

Schmidt, K. S., Pilewskie, P., Mayer, B., Wendisch, M., Kindel, B., Platnick, S., King, M. D., Wind, G., Arnold, G. T., Tian, L., Heymsfield, G., and Eichler, H.: Apparent Absorption of Solar Spectral Irradiance in Heterogeneous Ice Clouds, J. Geophys. Res., 115, D00J22, https://doi.org/10.1029/2009JD013124, 2010b.

Schmidt, S. and Pilewskie, P.: Airborne measurements of spectral shortwave radiation in cloud and aerosol remote sensing and energy budget studies, in: Light Scattering Reviews, edited by: 
Kokhanovsky, A. A., Vol. 6, Light Scattering and Remote Sensing of Atmosphere and Surface, Berlin, Heidelberg, Springer Berlin Heidelberg, 239-288, https://doi.org/10.1007/978-3-64215531-4_6, 2012.

Seidel, F. C. and Popp, C.: Critical surface albedo and its implications to aerosol remote sensing, Atmos. Meas. Tech., 5, 16531665, https://doi.org/10.5194/amt-5-1653-2012, 2012.

Smith, W. L., Hansen, C., Bucholtz, A., Anderson, B. E., Beckley, M., Corbett, J. G., Cullather, R. I., Hines, K. M., Hofton, M., Kato, S., Lubin, D., Moore, R. H., Segal Rosenhaimer, M., Redemann, J., Schmidt, S., Scott, R., Song, S., Barrick, J. D., Blair, J. B., Bromwich, D. H., Brooks, C., Chen, G., Cornejo, H., Corr, C. A., Ham, S., Kittelman, A. S., Knappmiller, S., LeBlanc, S., Loeb, N. G., Miller, C., Nguyen, L., Palikonda, R., Rabine, D., Reid, E. A., Richter-Menge, J. A., Pilewskie, P., Shinozuka, Y., Spangenberg, D., Stackhouse, P., Taylor, P., Thornhill, K. L., van Gilst, D., and Winstead, E.: Arctic radiation-icebridge sea and ice experiment: The Arctic radiant energy system during the critical seasonal ice transition, B. Am. Meteorol. Soc., 98, 1399-1426, https://doi.org/10.1175/BAMS-D-14-00277.1, 2017.

Song, S., Schmidt, K. S., Pilewskie, P., King, M. D., Heidinger, A. K., Walther, A., Iwabuchi, H., Wind, G., and Coddington, O. M.: The spectral signature of cloud spatial structure in shortwave irradiance, Atmos. Chem. Phys., 16, 13791-13806, https://doi.org/10.5194/acp-16-13791-2016, 2016.

Stamnes, K., Tsay, S.-C., Wiscombe, W., and Laszlo, I.: DISORT, a General-Purpose Fortran Program for Discrete-Ordinate-Method Radiative Transfer in Scattering and Emitting Layered Media: Documentation of Methodology, Tech. rep., Dept. of Physics and Engineering Physics, Stevens Institute of Technology, Hoboken, NJ 07030, 2000.
Twomey, S.: Atmospheric Aerosols, Section 12.3, Elsevier Scientific Publishing Co., UK, 278-290, 1977.

Wilcox, E. M. and Platnick, S.: Estimate of the impact of absorbing aerosol over cloud on the MODIS retrievals of cloud optical thickness and effective radius using two independent retrievals of liquid water path, J. Geophys. Res.-Atmos., 114, D05210, https://doi.org/10.1029/2008JD010589, 2009.

Winker, D. M., Tackett, J. L., Getzewich, B. J., Liu, Z., Vaughan, M. A., and Rogers, R. R.: The global 3-D distribution of tropospheric aerosols as characterized by CALIOP, Atmos. Chem. Phys., 13, 3345-3361, https://doi.org/10.5194/acp-133345-2013, 2013.

Zhang, Z., Meyer, K., Yu, H., Platnick, S., Colarco, P., Liu, Z., and Oreopoulos, L.: Shortwave direct radiative effects of above-cloud aerosols over global oceans derived from 8 years of CALIOP and MODIS observations, Atmos. Chem. Phys., 16, 2877-2900, https://doi.org/10.5194/acp-16-2877-2016, 2016.

Zuidema, P., Redemann, J., Haywood, J., Wood, R., Piketh, S., Hipondoka, M., and Formenti, P.: Smoke and clouds above the southeast Atlantic: Upcoming field campaigns probe absorbing aerosol's impact on climate, B. Am. Meteorol. Soc., 97, 11311135, https://doi.org/10.1175/BAMS-D-15-00082.1, 2016. 